\title{
Extensive Study of the Capabilities and Limitations of the CPA and SPC-SAFT Equations of State in Modeling a Wide Range of Acetic Acid Properties
}

Ribeiro, Rafael T. C. S.; Alberton, André L.; Paredes, Márcio L. L.; Kontogeorgis, Georgios M.; Liang, Xiaodong

Published in:

Industrial and Engineering Chemistry Research

Link to article, DOI:

10.1021/acs.iecr.8b00148

Publication date:

2018

Document Version

Peer reviewed version

Link back to DTU Orbit

Citation (APA):

Ribeiro, R. T. C. S., Alberton, A. L., Paredes, M. L. L., Kontogeorgis, G. M., \& Liang, X. (2018). Extensive Study of the Capabilities and Limitations of the CPA and SPC-SAFT Equations of State in Modeling a Wide Range of Acetic Acid Properties. Industrial and Engineering Chemistry Research, 57(16), 5690-5704.

https://doi.org/10.1021/acs.iecr.8b00148

\section{General rights}

Copyright and moral rights for the publications made accessible in the public portal are retained by the authors and/or other copyright owners and it is a condition of accessing publications that users recognise and abide by the legal requirements associated with these rights.

- Users may download and print one copy of any publication from the public portal for the purpose of private study or research.

- You may not further distribute the material or use it for any profit-making activity or commercial gain

- You may freely distribute the URL identifying the publication in the public portal 


\section{Thermodynamics, Transport, and Fluid Mechanics}

Subscriber access provided by DTU Library

\section{An extensive study of the capabilities and limitations of the CPA and SPC- SAFT equations of state in modeling a wide range of acetic acid properties}

Rafael Tini Cardoso Savattone Ribeiro, André Luis Alberton, Marcio

Luis Lyra Paredes, Georgios M. Kontogeorgis, and Xiaodong Liang

Ind. Eng. Chem. Res., Just Accepted Manuscript • DOI: 10.1021/acs.iecr.8b00148 • Publication Date (Web): 05 Apr 2018

Downloaded from http://pubs.acs.org on April 12, 2018

\section{Just Accepted}

"Just Accepted" manuscripts have been peer-reviewed and accepted for publication. They are posted online prior to technical editing, formatting for publication and author proofing. The American Chemical Society provides "Just Accepted" as a service to the research community to expedite the dissemination of scientific material as soon as possible after acceptance. "Just Accepted" manuscripts appear in full in PDF format accompanied by an HTML abstract. "Just Accepted" manuscripts have been fully peer reviewed, but should not be considered the official version of record. They are citable by the Digital Object Identifier (DOI@). "Just Accepted" is an optional service offered to authors. Therefore, the "Just Accepted" Web site may not include all articles that will be published in the journal. After a manuscript is technically edited and formatted, it will be removed from the "Just Accepted" Web site and published as an ASAP article. Note that technical editing may introduce minor changes to the manuscript text and/or graphics which could affect content, and all legal disclaimers and ethical guidelines that apply to the journal pertain. ACS cannot be held responsible for errors or consequences arising from the use of information contained in these "Just Accepted" manuscripts. 


\title{
An extensive study of the capabilities and limitations of the CPA and sPC-SAFT equations of state in modeling a wide range of acetic acid properties
}

\author{
Rafael T. C. S. Ribeiro ${ }^{1,2}$; André L. Alberton ${ }^{1}$; Márcio L. L. Paredes ${ }^{1}$; Georgios M. \\ Kontogeorgis ${ }^{2}$, Xiaodong Liang $^{2, *}$ \\ ${ }^{1}$ Programa de Pós-Graduação em Engenharia Química, Universidade do Estado do Rio de \\ Janeiro, Rua São Francisco Xavier, 524, Maracanã, Rio de Janeiro-RJ, Brasil \\ ${ }^{2}$ Center for Energy Resources Engineering (CERE), Department of Chemical and Biochemical \\ Engineering, Technical University of Denmark, 2800 Kongens Lyngby, Denmark \\ *Corresponding author: \\ E-mail address: xlia@kt.dtu.dk (Xiaodong Liang)
}

Keywords: Acetic Acid; PC-SAFT; CPA; Derivative Properties; Phase Equilibria 


\begin{abstract}
The accurate description of many thermodynamic properties of acetic acid and its mixtures can be a challenge to model with standard thermodynamic models like local-composition activity coefficient models and cubic equations of state. A possible solution is offered by association equations of state, e.g. those belonging to the Statistical Associating Fluid Theory (SAFT) family. While several researchers have studied the use of SAFT variants to model acetic acid properties (pure compound and mixtures), with few exceptions, those studies focused exclusively on phase equilibria including vapor pressure and density. Other important properties, such as the speed of sound, second virial coefficient, compressibility factor, enthalpy of vaporization, and the isobaric heat capacity have not been considered yet. Few studies investigate which is the appropriate association scheme to be used for acetic acid. In this work, we compare the capability of two association models, Cubic Plus Association (CPA) and simplified PerturbedChain SAFT (sPC-SAFT), to predict a wide range of properties of acetic acid (mixtures) including derivative properties. We evaluate the influence of including one or more of those properties in the parameter estimation procedure for SPC-SAFT, we compare the results obtained with various choices of the association schemes (one or two sites) and finally we evaluate the efficiency of CPA and SPC-SAFT in correlating the phase equilibria of the binary mixtures of acetic acid with water, hexane or ethanol. It is concluded that both equations of state perform overall similarly, with the one-site scheme performing better overall, especially for some properties. The results of the evaluation also show that some properties are inter-correlated in the parameter estimation process making it essentially impossible to obtain sets that can accurately describe all the properties of acetic acid.
\end{abstract}




\section{INTRODUCTION}

Acetic acid plays a very important role in the chemical industry. Despite the simplicity of its chemical formula, the interactions with other molecules make its study complex. The reason for this complexity is that this molecule can exhibit strong hydrogen bonds, forming dimers or higher oligomers in both vapor phase ${ }^{1,2}$ and liquid phase. ${ }^{3}$

The thermodynamic properties of acetic acid containing systems can be a challenge to model using standard thermodynamic models and it is hoped that better results may be obtained with association models, such as the SAFT variant models based on the perturbation theory proposed by Wertheim. ${ }^{4-7}$ Following the definition of Huang and Radosz, ${ }^{8}$ the acetic acid can be modelled using either one site (1A) or two-site (2B) associating scheme. The 1A scheme considers that the molecule has only one "glue-type" association site, allowing the formation of dimers between acetic acid molecules. In the $2 \mathrm{~B}$ scheme, the molecule has two association sites, allowing the formation of linear oligomer chains.

Many researchers have conducted studies with SAFT variants for modeling acetic acid properties and its mixtures, ${ }^{8-20}$ especially using the PC-SAFT and CPA equations of state (EOS).

Huang and Radosz $z^{8}$ expanded the SAFT framework to describe the vapor pressure and the density of acetic acid, $\mathrm{Fu}$ and Sandler $^{9}$ correlated the phase equilibria of binary mixtures containing acetic acid. Gross and Sadoski ${ }^{10}$ developed the perturbed-chain SAFT (PC-SAFT), and together with other authors ${ }^{11,15,18,20}$ obtained excellent results describing the vapor pressure and the density of acetic acid and in correlating phase equilibria. Derawi et al. ${ }^{12}$ applied the CPA EOS to carboxylic acids obtaining excellent results predicting the vapor pressure and the density of acetic acid and successfully correlating the phase equilibria of binary mixtures containing acetic acid but the model was only able to represent qualitatively the second virial coefficient. Breil et al. ${ }^{17}$ included data of the compressibility factor and the enthalpy of vaporization during the parameter estimation procedure of the CPA pure component parameters to obtain parameters that offered an excellent representation of the vapor pressure, the density, the compressibility factor and the enthalpy of vaporization of the acetic acid and successfully correlated its phase equilibria of binary mixtures. 
Table 1 summarizes several relevant studies from recent literature.

Table 1. Application of association models for acetic acid 
It is clear that, with few exceptions, ${ }^{12,17}$ these studies summarized above and in Table 1 only focused on phase equilibria, vapor pressure $\left(P_{s}\right)$ and density $(\rho)$, thus not evaluating the use of SAFT models in predicting other properties, such as the speed of sound $(u)$, second virial coefficient $(B)$, vapor phase compressibility factor $(Z)$, enthalpy of vaporization $\left(H_{v a p}\right)$, the isobaric heat capacity $\left(C_{p}\right)$ and the influence that the chosen association scheme may have in the representation of the various properties.

In this study, we aim to expand this knowledge by comparing the capability of CPA and the simplified PC-SAFT (sPC-SAFT) to predict or correlate such properties. We also compare the use of both of these equations of state in correlating phase equilibria of acetic acid and its mixtures, and propose new parameter sets for sPC-SAFT, evaluating the influence of including one or more of those properties in the parameter estimation procedure, and finally comparing the model performance with parameter sets that were previously proposed in the literature.

\section{MODELS}

PC-SAFT. The PC-SAFT equation of state was proposed by Gross and Sadowski ${ }^{10,25}$ and it is based on the theory of Wertheim ${ }^{4-7}$ for associating fluids. In this work, the sPC-SAFT proposed by von Solms et al. ${ }^{26}$ is used. It is a simplified version only in terms of mixing rules of the original model, which means the pure component parameters are the same. More information of the model can be found in the work of von Solms et al. ${ }^{26}$ The sPC-SAFT model is usually presented as the sum of contributions of the Helmholtz free energy expressed as:

$a^{r}=a^{h s}+a^{\text {chain }}+a^{\text {disp }}+a^{a s s o c}$

Equation 1

where $a^{r}$ is the reduced sum of contribution of the Helmholtz free energy, $a^{h s}$ is the contribution of the hard sphere, $a^{\text {chain }}$ is the contribution of the chain formation, $a^{\text {disp }}$ is the contribution of the dispersion forces, and $a^{a s s o c}$ is the association contribution expressed as: 
$a^{a s s o c}=\sum_{i} x_{i}\left[\sum_{A_{i}}\left(\ln X^{A_{i}}-\frac{X^{A_{i}}}{2}\right)+\frac{M_{i}}{2}\right]$

Equation 2

where $x_{i}$ is the molar fraction of the component $\mathrm{i}, M_{i}$ is the number of association sites of molecule $\mathrm{i}$, and $X^{A_{i}}$ is the fraction of molecules $\mathrm{i}$ at site $\mathrm{A}$ not bonded to other active sites, given by Equation 3:

$X^{A_{i}}=\frac{1}{1+\sum_{j} \sum_{B_{j}} \rho_{j} X^{B_{j}} \Delta^{A_{i} B_{j}}}$

Equation 3

where $\rho$ is the molar density and $\Delta^{A_{i} B_{j}}$ is the association strength between site A on molecule $\mathrm{i}$, and site $\mathrm{B}$ on molecule j, given by Equation 4:

$\Delta^{A_{i} B_{j}}=\sigma_{i j}^{3} g_{i j}^{h s} \kappa^{A_{i} B_{j}}\left[\exp \left(\frac{\epsilon^{A_{i} B_{j}}}{k T}\right)-1\right]$

Equation 4

where $\epsilon^{A_{i} B_{j}}$ and $\kappa^{A_{i} B_{j}}$ are the cross-association energy and volume respectively, and $g_{i j}^{h s}$ is the radial distribution function, expressed as:

$g^{h s}=\frac{1-\eta / 2}{(1-\eta)^{3}}$

Equation 5

where $\eta$ is calculated by Equation 6, and $d$ is the segment diameter, defined by Equation 7:

$$
\begin{aligned}
& \eta=\frac{\pi \rho}{6} \sum_{i} x_{i} m_{i} d_{i}^{3} \\
& d_{i}=\sigma_{i}\left[1-0.12 \exp \left(-\frac{3 \epsilon_{i}}{k T}\right)\right]
\end{aligned}
$$

Equation 6

Equation 7 
The parameters for the pair of unlike segments are calculated using the Berthelot-Lorentz combining rule: ${ }^{25}$

$$
\begin{aligned}
\sigma_{i j} & =\frac{\sigma_{i}+\sigma_{j}}{2} \\
\epsilon_{i j} & =\sqrt{\epsilon_{i} \epsilon_{j}}\left(1-k_{i j}\right)
\end{aligned}
$$

where $k_{i j}$ is the binary interaction parameter.

To calculate the cross section energy and area, we have used the near Elliott ${ }^{27}$ combining rule given as:

$$
\begin{aligned}
& \epsilon^{A_{i} B_{j}}=\frac{\epsilon^{A_{i} B_{i}}+\epsilon^{A_{j} B_{j}}}{2} \\
& \sigma_{i j}^{3} \kappa^{A_{i} B_{j}}=\sqrt{\kappa^{A_{i} B_{i}} \sigma_{i i}^{3} \kappa^{A_{j} B_{j}} \sigma_{j j}^{3}}
\end{aligned}
$$

CPA. The CPA EOS proposed by Kontogeorgis et al. ${ }^{28}$ combines a cubic equation of state for the physical part (e.g. SRK) with the association term from SAFT theory. ${ }^{28}$ The CPA EOS for mixtures can be expressed in terms of pressure $(P)$ as:

$$
P=\frac{R T}{V_{m}-b}-\frac{a(T)}{V_{m}\left(V_{m}+b\right)}-\frac{1}{2} \frac{R T}{V_{m}}\left(1+\rho \frac{\partial \ln g}{\partial \rho}\right) \sum_{i} x_{i} \sum_{A_{i}}\left(1-X^{A_{i}}\right)
$$

where $\rho$ is the molar density, $a$ is the energy parameter, and $b$ is the co-volume. 
The $X^{A_{i}}$ term is calculated almost in the same way as in PC-SAFT, with the difference that $\Delta^{A_{i} B_{j}}$ is now expressed as:

$\Delta^{A_{i} B_{j}}=b_{i j} g_{i j} \beta^{A_{i} B_{j}}\left[\exp \left(\frac{\epsilon^{A_{i} B_{j}}}{k T}\right)-1\right]$

Equation 13

where $\beta^{A_{i} B_{j}}$ is the association volume and $g_{i j}$ is defined by

$g_{i j}=\frac{1}{1-1.9\left(b_{i j} / 4 V_{m}\right)}$

Equation 14

The cross parameters for CPA are calculated by

$b_{i j}=\frac{b_{i}+b_{j}}{2}$

Equation 15

$a_{i j}=\sqrt{a_{i} a_{j}}\left(1-k_{i j}\right)$

Equation 16

where $k_{i j}$ is the binary interaction parameter.

To calculate the cross-association energy $\left(\epsilon^{A_{i} B_{j}}\right)$ and the cross-association volume $\left(\beta^{A_{i} B_{j}}\right)$ we have used the near Elliott combining rule ${ }^{27}$, which for CPA is given by the following equations:

$\epsilon^{A_{i} B_{j}}=\frac{\epsilon^{A_{i} B_{i}}+\epsilon^{A_{j} B_{j}}}{2}$

Equation 17

$\beta^{A_{i} B_{j}}=\sqrt{\beta^{A_{i} B_{i}} \beta^{A_{j} B_{j}}} \frac{\sqrt{b_{i} b_{j}}}{b_{i j}}$

Equation 18 


\section{PROPERTIES EVALUATED}

We have in this work evaluated the performance of SPC-SAFT and CPA in predicting the vapor pressure $\left(P_{s}\right)$, density $(\rho)$, speed of sound $(u)$, second virial coefficient $(B)$, compressibility factor $(Z)$, enthalpy of vaporization $\left(H_{v a p}\right)$ and the isobaric heat capacity $\left(C_{p}\right)$, for the acetic acid considering both the one-site (1A) and two-site (2B) association schemes. The terminology of Huang and $\operatorname{Radosz}^{8}$ is used for the association schemes.

All sets were evaluated under the same conditions. The saturated pressure $\left(P_{s}\right)$, the density $(\rho)$ and the enthalpy of vaporization $\left(H_{v a p}\right)$ were evaluated in the temperature range of 293 - $543 \mathrm{~K}$ against the data from DIPPR. ${ }^{29}$ The speed of sound $(u)$ was evaluated at atmospheric pressure in the temperature range 293 - $353 \mathrm{~K}$ against the data from Goodman and Whittenburg $^{30}$ that was available at the Dortmund Data Bank. ${ }^{31}$ The second virial coefficient was evaluated in the temperature range $410-574 \mathrm{~K}$ using the data of Bich et al. ${ }^{32}$ to fit the virial equation $\left(B_{1}\right)$ and the methodology proposed by Tsonopoulos and Prausnitz ${ }^{1}\left(B_{2}\right)$ to obtain its experimental value. The compressibility factor $(Z)$ was evaluated in the temperature range $373-$ $503 \mathrm{~K}$, against the data from Freeman and Wilson. ${ }^{33}$ The isobaric heat capacity $\left(C_{p}\right)$ was evaluated at the temperature ranges $290-380 \mathrm{~K}$. In order to calculate the speed of sound and the isobaric heat capacity is necessary to know the ideal gas heat capacity $\left(C_{p}{ }^{i d}\right) .{ }^{34,35}$ This was taken from the DIPPR ${ }^{29}$ correlation that presented a deviation lower than $1 \%$ from the experimental points. The relative equations can be found in the literature. ${ }^{34,35}$ The number of data points used in the evaluation of each property is respectively, 59, 30, 31, 12, 21, 49 and 11.

Because of its associative nature, the acetic acid has low values for the compressibility factor $^{33}$ and quite low negative values for the second virial coefficient. ${ }^{1,12,36,37} \mathrm{We}$ compared the use of SPC-SAFT and CPA to see if the association theory models can consider these trends.

The values for the compressibility factor were taken from Freeman and Wilson. ${ }^{33}$ There is no clear consensus in the literature on how we can determine the experimental value of the second virial coefficient for the acetic acid. ${ }^{1,2,32,36,37}$ We have, thus, chosen two approaches for representing the second virial coefficient data. 
The first one $\left(B_{1}\right)$ is by fitting the $P \rho T$ data with the "classical" virial equation truncated in the third term. ${ }^{38,39}$ In this method we used the data from Bich et al. ${ }^{32}$

$$
\frac{P}{R T}=\rho+B(T) \rho+C(T) \rho^{2}
$$

The second approach $\left(B_{2}\right)$ considers the relation of the second virial coefficient with the dimerization constant. ${ }^{1,32,36,37}$ This approach is better explained elsewhere. ${ }^{1,32,36,37}$ A simplified explanation is that at low temperatures, the negative values of the dimerization constant $\left(\mathrm{K}_{2}\right)$ can be used to calculate the second virial coefficient through the relation:

$K_{2}=\frac{-B_{\text {exp }}}{R T}$

Equation 20

Tsonopoulos and Prausnitz ${ }^{1}$ proposed a correlation for the dimerization constant for temperatures above $353.15 \mathrm{~K}$ :

$-\log _{10} K_{2}\left(m m \mathrm{Hg}^{-1}\right)=10.1-\frac{3040}{T}$

Equation 21

Combining Equation 20 and 21 it is possible to obtain the pseudo experimental values of the second virial coefficient

The calculated values of the second virial coefficient were obtained numerically by using the $\lim _{P \rightarrow 0} \frac{Z-1}{\rho}=B$ and with the $P \rho T$ data of Bich et al. ${ }^{32}$

The deviations of the various properties were calculated using the percentage average absolute deviation, AAD (\%):

$$
A A D(\%)=\frac{1}{N} \sum_{i=1}^{N} \frac{\left|\theta_{i}^{\text {calc }}-\theta_{i}^{\text {exp }}\right|}{\theta_{i}^{\text {exp }}} * 100
$$

where $\theta$ represents the evaluated property (i.e. $P_{s}, u$, etc.) and $i$ is the data index. 


\section{PARAMETERIZATION}

sPC-SAFT has five adjustable parameters: the segment number, $m$, the segment diameter, $\sigma$, the segment energy, $\epsilon / k$, the effective association volume, $\kappa^{A B}$, and the association energy, $\epsilon^{A B} / k$. These parameters are often obtained by fitting the data of vapor pressure and density, ${ }^{10,11,15,25}$ but this could lead to parameters that may not satisfactorily represent other properties, e.g. sound velocity, second virial coefficient, compressibility factor, enthalpy of vaporization and heat capacity. In this work we evaluated the influence that these properties may have if included in the parameter estimation procedure. This was done by including one or more of those properties in the objective function during the parameter estimation procedure, considering both association schemes (1A and $2 \mathrm{~B}$ ) and both ways of calculating the second virial coefficient as mentioned in the properties evaluated section, this approach has led to many parameter sets. The sets that presented an AAD higher than $10 \%$ in vapor pressure or density where immediately discarded. The remaining sets were evaluated by plotting the AAD of vapor pressure, density, speed of sound, compressibility factor, enthalpy of vaporization, heat capacity and the average between these properties as a pair in a two-dimensional scatterplot matrix.

The scatterplot matrix is created by plotting of the variables on a single page in a matrix format, each row and column defines a single scatterplot. For example, given a set of variables, $A_{1}, A_{2}, \ldots A_{j}$, where $A_{j} \in\left\{P_{s}, \rho, u, B, Z, H_{v a p}, C_{P}\right.$, their average $\}$ with $A$ being the AAD of the property and $j$ is the number of variables, the scatterplot matrix will have $j-1$ rows and $j-1$ columns, and the $i$ th row and $j$ th column of this matrix is a plot of deviations in $A_{i}$ versus deviations in $A_{j}$. More details are referred to the reference. ${ }^{40}$ The same methodology was applied to the parameters obtained. This was done in order to try to identify a correlation between them and/or the average of the properties.

Objective function and minimization procedure. The objective function used to fit the data was the sum of the AAD (\%) of the evaluated properties: 


$$
\begin{aligned}
& \text { Fobj }=\frac{\varphi^{P_{s}}}{N_{P_{s}}} \sum_{i}^{N_{P_{s}}}\left|\frac{P_{s_{i}}^{\text {calc }}-P_{s_{i}}^{\text {exp }}}{P_{s_{i}}^{\exp }}\right|+\frac{\varphi^{\rho}}{N_{\rho}} \sum_{i}^{N \rho}\left|\frac{\rho_{i}^{\text {calc }}-\rho_{i}^{\text {exp }}}{\rho_{i}^{\exp }}\right| \\
& +\frac{\varphi^{u}}{N_{u}} \sum_{i}^{N_{u}}\left|\frac{u_{i}^{c a l c}-u_{i}^{\text {exp }}}{u_{i}^{\exp }}\right|+\frac{\varphi^{B}}{N_{B}} \sum_{i}^{N_{B}}\left|\frac{B_{i}^{\text {calc }}-B_{i}^{\text {exp }}}{B_{i}^{\text {exp }}}\right| \\
& +\frac{\varphi^{Z}}{N_{z}} \sum_{i}^{N_{z}}\left|\frac{Z_{i}^{\text {calc }}-Z_{i}^{\text {exp }}}{Z_{i}^{\text {exp }}}\right|+\frac{\varphi^{H v a p}}{N_{H_{v a p}}} \sum_{i}^{N_{H_{v a p}}}\left|\frac{H v a p_{i}^{\text {calc }}-H v a p_{i}^{\text {exp }}}{H_{v a p}^{\text {exp }}}\right| \\
& +\frac{\varphi^{C p}}{N_{C p}} \sum_{i}^{N_{C p}}\left|\frac{C p_{i}^{c a l c}-C p_{i}^{e x p}}{C p_{i}^{e x p}}\right| \text {. }
\end{aligned}
$$

where $\varphi^{j}, j \in\left\{P_{S}, \rho, u, B, Z, H_{v a p}, C_{P}\right\}$ represents a binary variable, which can assume 0 or 100 , depending on the response variable considered in the minimization of the objective function. For $P_{S}$ and $\rho, \varphi^{j}$ is always 100. $N_{P_{S}}, N_{\rho}, N_{u}, N_{B}, N_{Z}, N_{H_{v a p}}$ and $N_{C_{P}}$ are the number of experimental points for vapor pressure, density, speed of sound, second virial coefficient, compressibility factor, enthalpy of vaporization and isobaric heat capacity, respectively. And $i$ is the evaluated experimental data point.

The minimization procedure used was the particle swarm optimization (PSO) ${ }^{41}$ which is very simple to implement and is commonly used in the optimization of nonlinear problems. This algorithm is described elsewhere. ${ }^{42-44}$

The upper and lower limits of parameters considered in PSO are presented in Table 2. This range was chosen based on the literature cited on Table 1 as well as our preliminary results estimating parameters with the PSO for the acetic acid pure component parameters sets, where we increased the search range for the optimum parameters when the estimation led to multiple values very close or at one of the imposed parameter search limits. 
Table 2. Upper and lower limits used in the particle swarm settings during the estimation for the pure component parameters.

\begin{tabular}{cccccccc}
\hline & $m$ & $\sigma$ & $\epsilon / k$ & $\kappa^{A B}$ & $\epsilon^{A B} / k$ & $\mathrm{~N}_{\mathrm{p}}{ }^{\mathrm{a}}$ & $\mathrm{N}_{\mathrm{i}}{ }^{\mathrm{a}}$ \\
\hline Upper Limit & 4 & 4 & 400 & 1 & 9000 & 80 & 60 \\
Lower Limit & 2 & 2 & 100 & $1 \mathrm{e}-6$ & 1000 & 40 & 20 \\
\hline
\end{tabular}

${ }^{a} \mathrm{~N}_{\mathrm{p}}$ and $\mathrm{N}_{\mathrm{i}}$, are the number of particles and number of interactions, respectively. Its upper limit represents the values used during the parameter estimation of the model and the lower limit represents the values used during the estimation of the binary interaction parameter

Binary interaction parameter. To fit the binary interaction parameter $\left(k_{i j}\right)$ for vapor-liquid equilibrium calculations, we used as the objective function the percentage average absolute deviation in the temperature or in the pressure plus the deviation in the relative volatility between water and acetic acid $(\alpha)$, as shown below:

$$
\begin{aligned}
& \operatorname{ObjF}_{T}=\frac{1}{N} \sum_{i=1}^{N} \frac{\left|T_{i}^{\text {calc }}-T_{i}^{\text {exp }}\right|}{T_{i}^{\text {exp }}} * 100+\frac{1}{N} \sum_{i=1}^{N} \frac{\left|\alpha_{i}^{\text {calc }}-\alpha_{i}^{\text {exp }}\right|}{\alpha_{i}^{\text {exp }}} * 100 \\
& \operatorname{Obj}_{P}=\frac{1}{N} \sum_{i=1}^{N} \frac{\left|P_{i}^{\text {calc }}-P_{i}^{\text {exp }}\right|}{P_{i}^{\text {exp }}} * 100+\frac{1}{N} \sum_{i=1}^{N} \frac{\left|\alpha_{i}^{\text {calc }}-\alpha_{i}^{\text {exp }}\right|}{\alpha_{i}^{\text {exp }}} * 100
\end{aligned}
$$

Equation 25

\section{RESULTS}

New sets. Various parameter sets were obtained for the pure acetic acid using SPC-SAFT. The results of the AAD (\%) for all the evaluated properties with the different sets were plotted as a pair in a two-dimensional scatter plot matrix. A similar representation was done for the obtained parameter sets and the average of the cited properties. This is presented in Figures 1 and 2. 

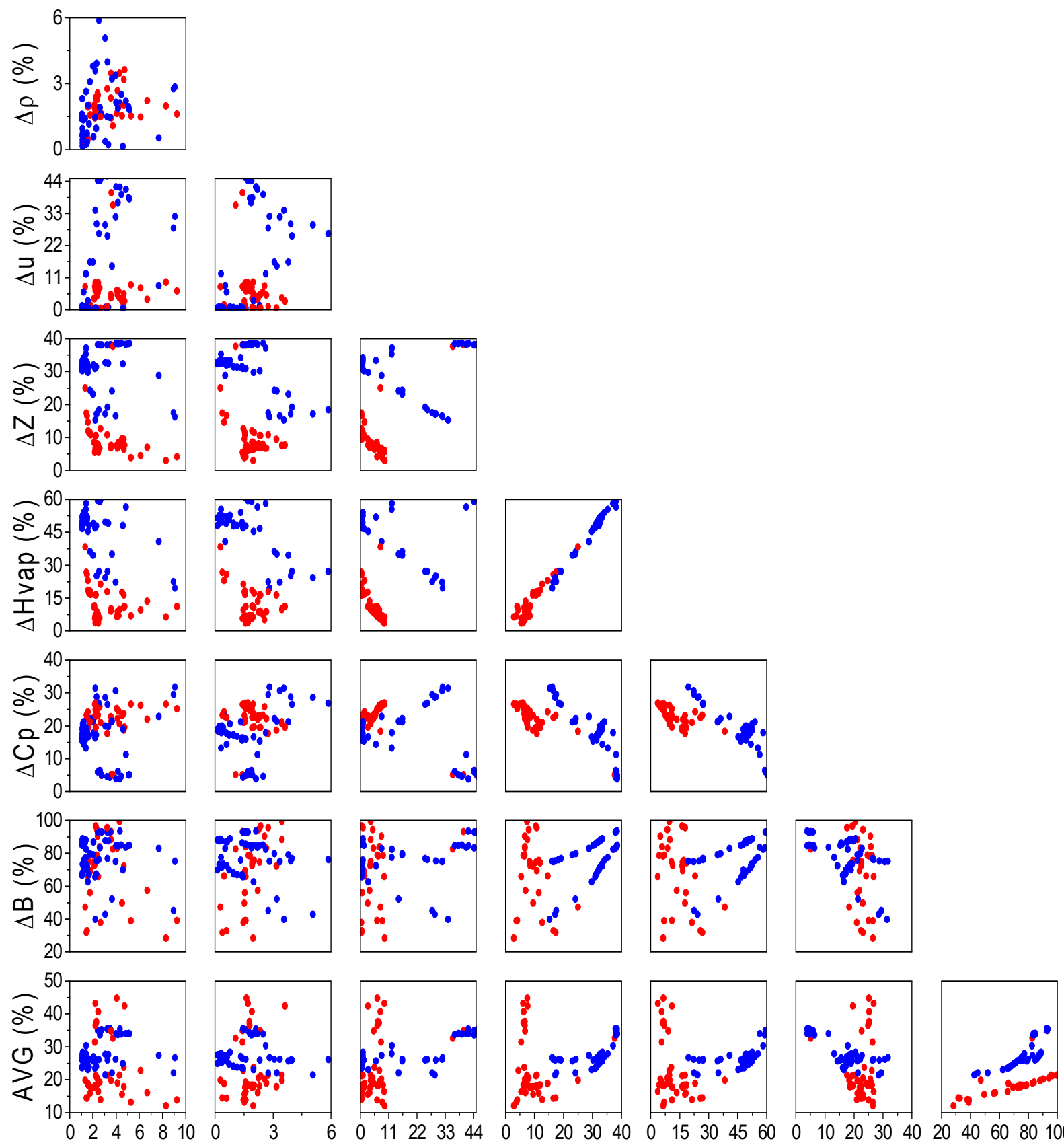

$\Delta$ Psat (\%)

$\Delta \rho(\%)$

$\Delta \mathrm{u}(\%)$

$\Delta Z(\%)$

$\Delta \mathrm{Hvap}(\%)$

$\Delta \mathrm{Cp}(\%)$

$\Delta \mathrm{B}(\%)$

Figure 1. Two-dimensional scatter plot matrix of the AAD (\%) for vapor pressure $\left(P_{s}\right)$, density $(\rho)$, speed of sound $(u)$, compressibility factor $(Z)$, enthalpy of vaporization $\left(H_{v a p}\right)$, heat capacity $\left(C_{p}\right)$, second virial coefficient (B) and their average (AVG), plotted as a pair. Results are for the sets obtained for sPC-SAFT. X,Y-axis units are in \%. ๑Results for the 1A scheme; •Results for the $2 \mathrm{~B}$ scheme 
From the analysis of Figure 1 it is possible to see that some properties are intercorrelated.

The deviations of the enthalpy of vaporization and of the compressibility factor have the same behavior. This means that it is not necessary to use both of these properties in the parameter estimation procedure and that if a set is able to predict one of these properties, it will also predict the other. This result may be expected since we excluded parameter sets with high deviations in vapor pressure or liquid density, and the model correlates well the ratio enthalpy of vaporization over variation in volume in the vaporization.

The speed of sound seems to have an inverse relation with the enthalpy of vaporization making it impossible for the model to describe both properties with the same pure component parameters. Besides, the model will not be able to predict the isobaric heat capacity together with the other properties.

The analysis of the scatter pattern of the deviations for $P_{s}$ and $\rho$ also shows that both association schemes can lead to sets that have a good prediction for these two properties, with the $2 \mathrm{~B}$ scheme having the lowest deviation for the two properties. The lower average deviations are obtained with the use of the $1 \mathrm{~A}$ scheme and this scheme is the recommended if a single parameter set will be used to correlate several properties simultaneously. 

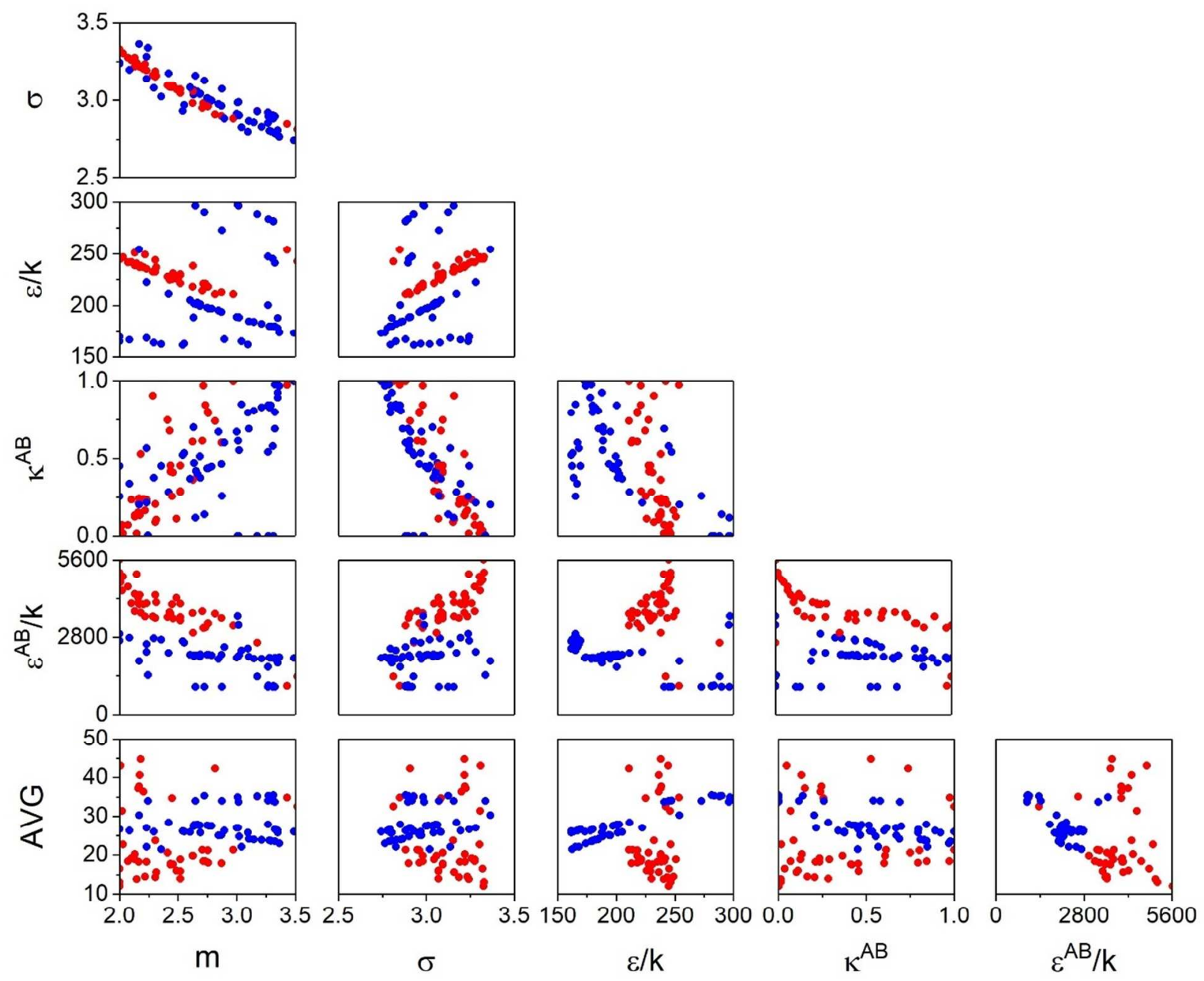

Figure 2. Scatter plot of each pair of parameters and average of the evaluated properties with the different sets obtained for sPC-SAFT. -Results for the 1A scheme; - Results for the 2B scheme

The analysis of Figure 2 shows that the parameters that can lead to better results with the 1A scheme are in the $5000-5600 \mathrm{~K}$ range of the association energy, getting closer to the experimental values reported for the association energy of the acetic acid ${ }^{17}$ meaning that the $1 \mathrm{~A}$ scheme used in the evaluated models is theoretically more correct compared to the $2 \mathrm{~B}$ scheme, at least for pure acetic acid, but this does not necessarily mean that all the properties will be accurately represented. The better results were obtained with scheme $1 \mathrm{~A}$ and $\mathrm{m}$ about $2, \sigma$ about $3.3 \AA, \varepsilon / k$ about $240 \mathrm{~K}$ and low $\kappa^{A B}$. It was possible to identify some clear correlations between 
the parameters (i.e. $\sigma \times m$ or $\sigma \times \kappa^{A B}$ ) this are expected results as the van der Walls volume is proportional to $m \sigma^{3}$ and should be constant in the optimal parameters. Because of these reasons, we conclude that it is impossible to obtain a single pure compound parameter set to represent all the properties of acetic acid. This is especially the case because a lower AAD for the compressibility factor, enthalpy of vaporization and heat capacity can lead to parameters that cannot describe the vapor pressure or/and the density satisfactorily.

In the absence of a clear set to use, the sets presented in this work were chosen among those showing the lowest deviation average between vapor pressure, density, speed of sound, compressibility factor, enthalpy of vaporization and heat capacity, and presented deviations lower than $2 \%$ in vapor pressure and density. With these conditions, the most successful sets, for both schemes, were the ones fitted using the data from DIPPR ${ }^{29}$ for vapor pressure and density, in the temperature range of 0.5-0.97 $T_{r}$, and the data for the speed of sound from the Dortmund Data Bank. ${ }^{31}$

In the next section, these new sets are presented together with sets that were available in the literature for both sPC-SAFT and CPA. All sets used are shown in Table 3 and 4.

Pure properties evaluation. In this work, several sets of parameters for the acetic acid were evaluated using PC-SAFT and CPA. They are presented in Table 3 and 4 and were named as follows $(\mathrm{TW}=$ this work $=$ new parameter sets estimated in this work $)$ :

- For the acetic acid using the $2 \mathrm{~B}$ scheme - PC-SAFT $2 \mathrm{~B} 1,{ }^{10}$ PC-SAFT $2 \mathrm{~B} 2,{ }^{11}$ PC-SAFT TW 2B(new), CPA 2B; ${ }^{12}$

- For the acetic acid using the $1 \mathrm{~A}$ scheme - PC-SAFT $1 \mathrm{~A} 1,{ }^{18}$ PC-SAFT $1 \mathrm{~A} 2,{ }^{15}$ PC-SAFT TW 1A(new), CPA $1 \mathrm{~A} 1,{ }^{12} \mathrm{CPA} 1 \mathrm{~A} 2,{ }^{17} \mathrm{CPA} 1 \mathrm{~A} 3,{ }^{17}$ 
Table 3. Pure component parameters set for sPC-SAFT

\begin{tabular}{cccccccccc}
\hline \multirow{2}{*}{ Sets } & $m$ & $\sigma$ & $\epsilon / k$ & $\kappa^{A B}$ & $\epsilon^{A B} / k$ & Scheme & Ps & \multirow{2}{*}{ ref } \\
& $(-)$ & $(\AA)$ & $(\mathrm{K})$ & $(-)$ & $(\mathrm{K})$ & & $T_{r}$ range & \\
\hline PC-SAFT 2B1 & 1.340 & 3.858 & 211.6 & 0.075 & 3044 & $2 \mathrm{~B}$ & $0.51-0.99$ & 10 \\
PC-SAFT 2B2 & 2.342 & 3.185 & 199.9 & 0.260 & 2456 & $2 \mathrm{~B}$ & $0.51-0.96$ & 11 \\
PC-SAFT 1A1 & 1.983 & 3.309 & 238.8 & 0.001 & 7133 & $1 \mathrm{~A}$ & $0.50-0.98$ & 18 \\
PC-SAFT 1A2 & 1.503 & 3.701 & 286.1 & 0.007 & 5248 & $1 \mathrm{~A}$ & $0.51-0.91$ & 15 \\
PC-SAFT TW 2B & 2.689 & 3.041 & 201.5 & 0.376 & 2187 & $2 \mathrm{~B}$ & $0.50-0.97$ & TW \\
PC-SAFT TW 1A & 2.220 & 3.233 & 248.7 & 0.165 & 3543 & $1 \mathrm{~A}$ & $0.50-0.97$ & $\mathrm{TW}$ \\
\hline
\end{tabular}

Table 4. Pure component parameters set for CPA

\begin{tabular}{|c|c|c|c|c|c|c|c|c|}
\hline \multirow{2}{*}{ Sets } & & & & & $\begin{array}{c}\beta^{A B} \\
\left(\times 10^{3}\right)\end{array}$ & Ps & $\rho$ & \multirow{2}{*}{ ref } \\
\hline & bar L ${ }^{2} \mathrm{~mol}^{-2}$ & $\mathrm{~L} \mathrm{~mol}^{-1}$ & $(-)$ & $(\mathrm{K})$ & $(-)$ & \multicolumn{2}{|l|}{$T_{r}$ range } & \\
\hline CPA 1A1 & 9.119 & 0.0468 & 0.464 & 4850 & 4.5 & \multirow{4}{*}{$0.50-0.91$} & & 12 \\
\hline CPA 1 A 2 & 8.296 & 0.0455 & 0.494 & 5789 & 1.6 & & & 17 \\
\hline CPA $1 \mathrm{~A} 3$ & 8.199 & 0.0453 & 0.506 & 5867 & 1.5 & & & 17 \\
\hline CPA 2B & 7.059 & 0.0478 & 0.880 & 2263 & 140 & & & 12 \\
\hline
\end{tabular}

All sets were evaluated under the same conditions. The saturated pressure $\left(P_{s}\right)$, the density $(\rho)$ and the enthalpy of vaporization $\left(H_{v a p}\right)$ were evaluated in the temperature range of $293-543$ $\mathrm{K}$ against the data from DIPPR. ${ }^{29}$ The speed of sound $(u)$ was evaluated at atmospheric pressure in the temperature range 293 - $353 \mathrm{~K}$ against the data from the Dortmund Data Bank. ${ }^{31}$ The second virial coefficient was evaluated in the temperature range $410-574 \mathrm{~K}$ using the data of Bich et al. ${ }^{32}$ to fit the virial equation $\left(B_{1}\right)$ and the methodology proposed by Tsonopoulos and Prausnitz ${ }^{1}\left(B_{2}\right)$ to obtain its experimental value. The compressibility factor $(Z)$ was evaluated in the temperature range $373-503 \mathrm{~K}$, against the data from Freeman and Wilson. ${ }^{33}$ The isobaric heat capacity $\left(C_{p}\right)$ were evaluated using the DIPPR correlations ${ }^{29}$ at the temperature ranges $290-$ $380 \mathrm{~K}$.

The performance of the two models was compared by calculating the AAD (\%) for the above mentioned properties with each set. These results are presented in Table 5. 
Table 5. Average absolute deviation (\%) for the pure component properties.

\begin{tabular}{cccccccccc}
\hline Sets & $P_{s}{ }^{l}$ & $\rho^{l}$ & $u^{2}$ & $Z^{3}$ & $H_{\text {vap }}{ }^{l}$ & $C_{p}{ }^{l}$ & $A V G^{4}$ & $B_{1}{ }^{5}$ & $B_{2}{ }^{6}$ \\
\hline PC-SAFT 2B1 & 2.16 & 0.64 & 28.0 & 22.8 & 34.8 & 34.4 & 20.5 & 78.4 & 49.7 \\
PC-SAFT 2B2 & 1.24 & 1.20 & 9.1 & 30.5 & 47.6 & 23.2 & 18.8 & 85.8 & 66.7 \\
\cline { 2 - 5 } PC-SAFT TW 2B & 1.45 & 0.23 & 0.70 & 33.3 & 52.7 & 18.7 & 17.8 & 88.6 & 73.1 \\
\hline PC-SAFT TW 1A & 1.44 & 0.38 & 0.53 & 17.3 & 26.7 & 23.1 & 11.6 & 69.0 & 31.7 \\
PC-SAFT 1A1 & 0.86 & 2.49 & 13.1 & 17.8 & 12.0 & 27.9 & 12.4 & 385 & 949 \\
PC-SAFT 1A2 & 0.97 & 0.16 & 10.5 & 4.18 & 7.91 & 31.3 & 9.17 & 36.3 & 83.7 \\
\hline CPA 2B & 1.15 & 0.26 & 4.58 & 31.4 & 49.0 & 19.6 & 17.7 & 86.4 & 68.1 \\
\hline CPA 1A1 & 1.11 & 0.17 & 12.2 & 14.2 & 21.3 & 33.2 & 13.7 & 60.5 & 14.2 \\
CPA 1A2 & 1.45 & 1.15 & 17.3 & 2.73 & 4.99 & 34.0 & 10.3 & 21.2 & 110 \\
CPA 1A3 & 1.49 & 1.31 & 17.6 & 3.07 & 3.64 & 33.9 & 10.2 & 25.0 & 136 \\
\hline
\end{tabular}

1 Data from DIPPR, ${ }^{29} 2$ Data from Dortmund Data Bank, ${ }^{31} 3$ Data from Freeman and Wilson; ${ }^{33} 4$ average calculated without the values of B; 5 Data from Tsonopoulos and Prausnitz ${ }^{1} ; 6$ Data from Bich et al.; ${ }^{32}$ The properties inside the rectangle were used in the parameter estimation procedure

All sets can represent well the vapor pressure and the density data of pure acetic acid. In pipe flows is important to know the speed of sound, in this aspect the inclusion of the speed of sound in the parameter estimation procedure lead to parameters that could simulate this property with low deviations, namely sPC-SAFT parameter sets PC-SAFT TW 1A, PC-SAFT TW 2B.

The sPC-SAFT parameter set PC-SAFT 1A2 had the best overall performance and was the only set of PC-SAFT that was able to represent the compressibility factor and the enthalpy of vaporization with low deviations.

The sets PC-SAFT 1A2, CPA 1A2 and CPA 1A3 have similar values for the parameter of the association energy, in the region of $5000-6000 \mathrm{~K}$. These parameters had a better performance in describing the compressibility factor and the enthalpy of vaporization. This region is still a bit far from the experimental region reported in the literature $(7000-8000 \mathrm{~K}){ }^{17}$ and the set that had the association value in this range (PC-SAFT 1A1), didn't perform as well as the aforementioned three sets.

The sets PC-SAFT TW 2B and CPA 2B were able to describe qualitatively the results of the isobaric heat capacity, but no set was able to perform quantitatively well. 
The results obtained from the AAD of the properties for the different sets confirm the tendency that when a parameter set had a rather good representation of a property, this comes at the cost of reducing the accuracy for the speed of sound. This tendency is clearly seen from the results of the sets CPA 2B, CPA 1 A3 and PC-SAFT 1 A2.

Overall, the best correlation of properties of liquid phase and vapor pressure were obtained with the parameter sets presented in this work, with deviations below $1.45 \%$ for vapor pressure, liquid density and liquid speed of sound. Also, the lower deviations for liquid heat capacity were also obtained with the parameters presented here. Some results are plotted in Figures $3-10$.

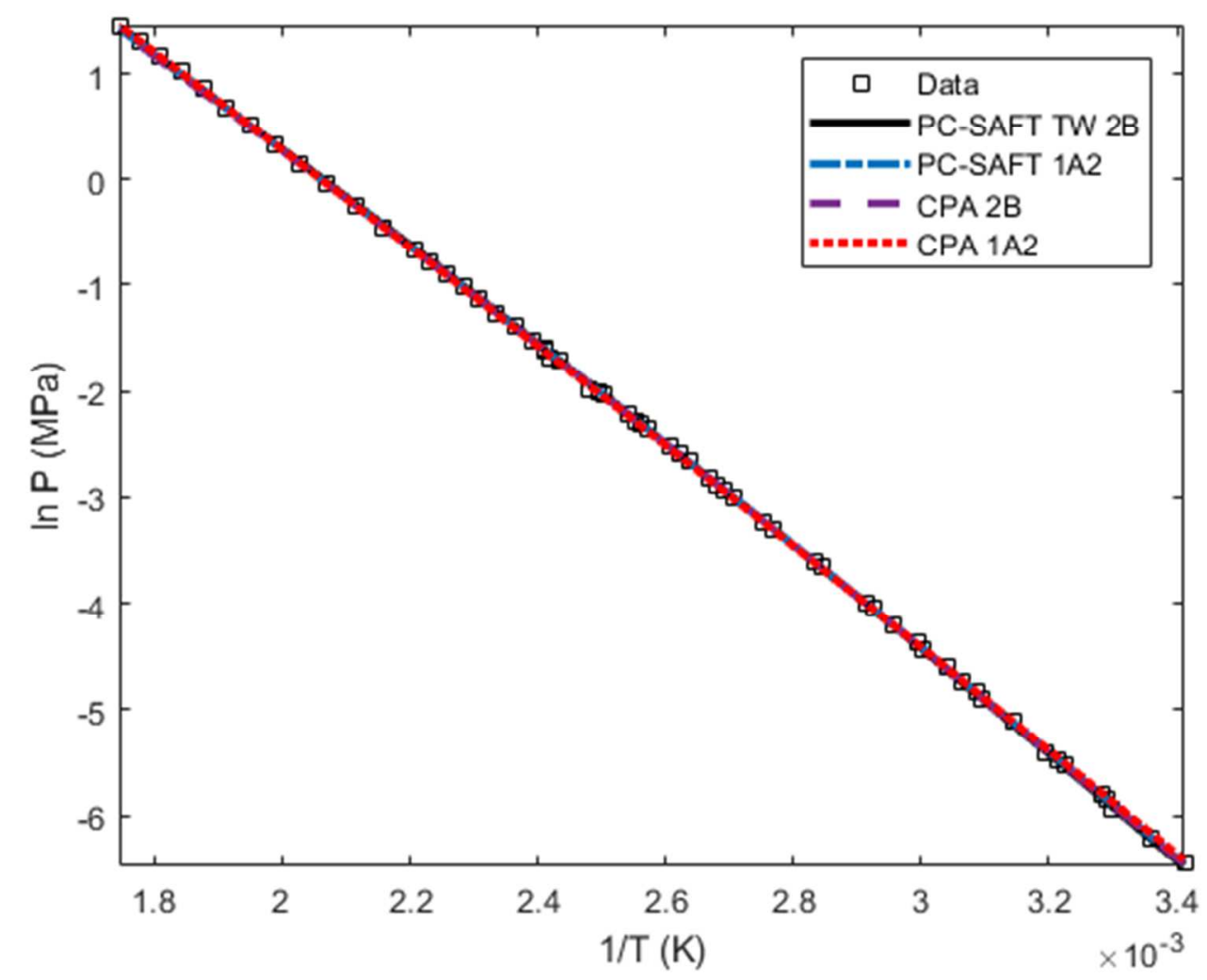

Figure 3. Experimental and calculated vapor pressure of acetic acid with sPC-SAFT and CPA using different parameters sets. Data are taken from DIPPR ${ }^{29}$, 


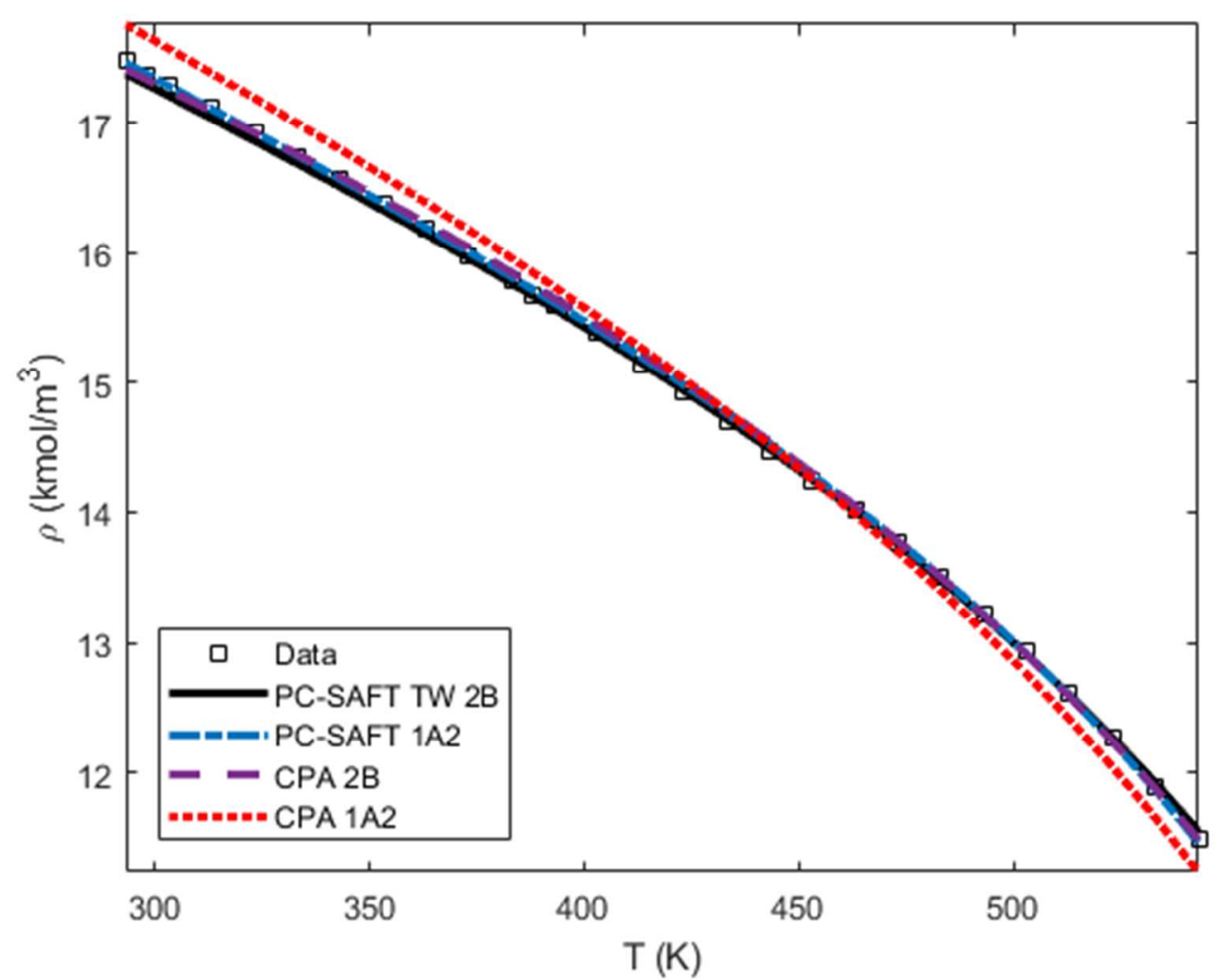

Figure 4. Experimental and calculated density of acetic acid with SPC-SAFT and CPA using different parameters sets. Data are taken from DIPPR ${ }^{29}$ 


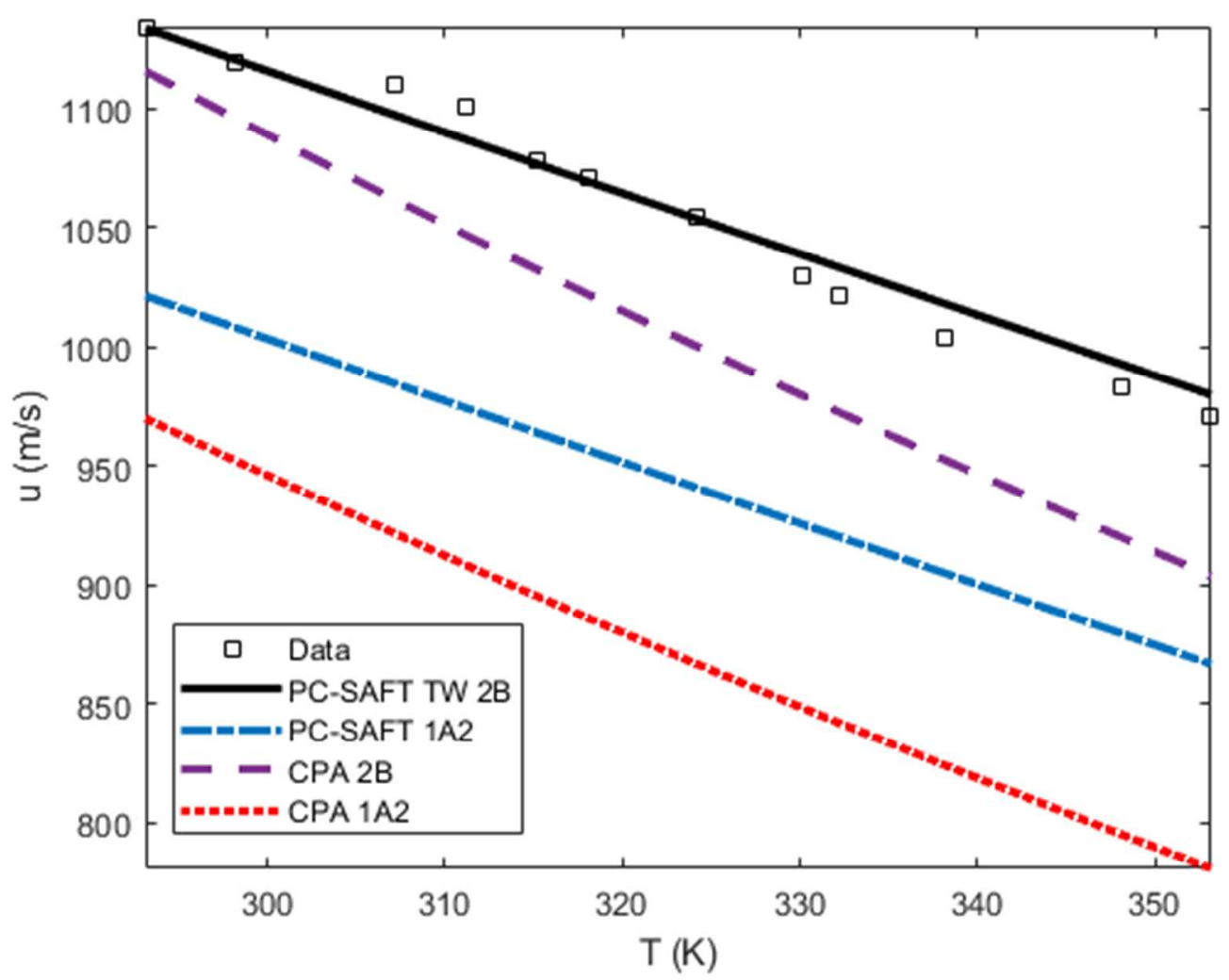

Figure 5. Experimental and calculated speed of sound of acetic acid with sPC-SAFT and CPA using different parameters sets. Data are taken from Dortmund Data Bank ${ }^{31}$ 


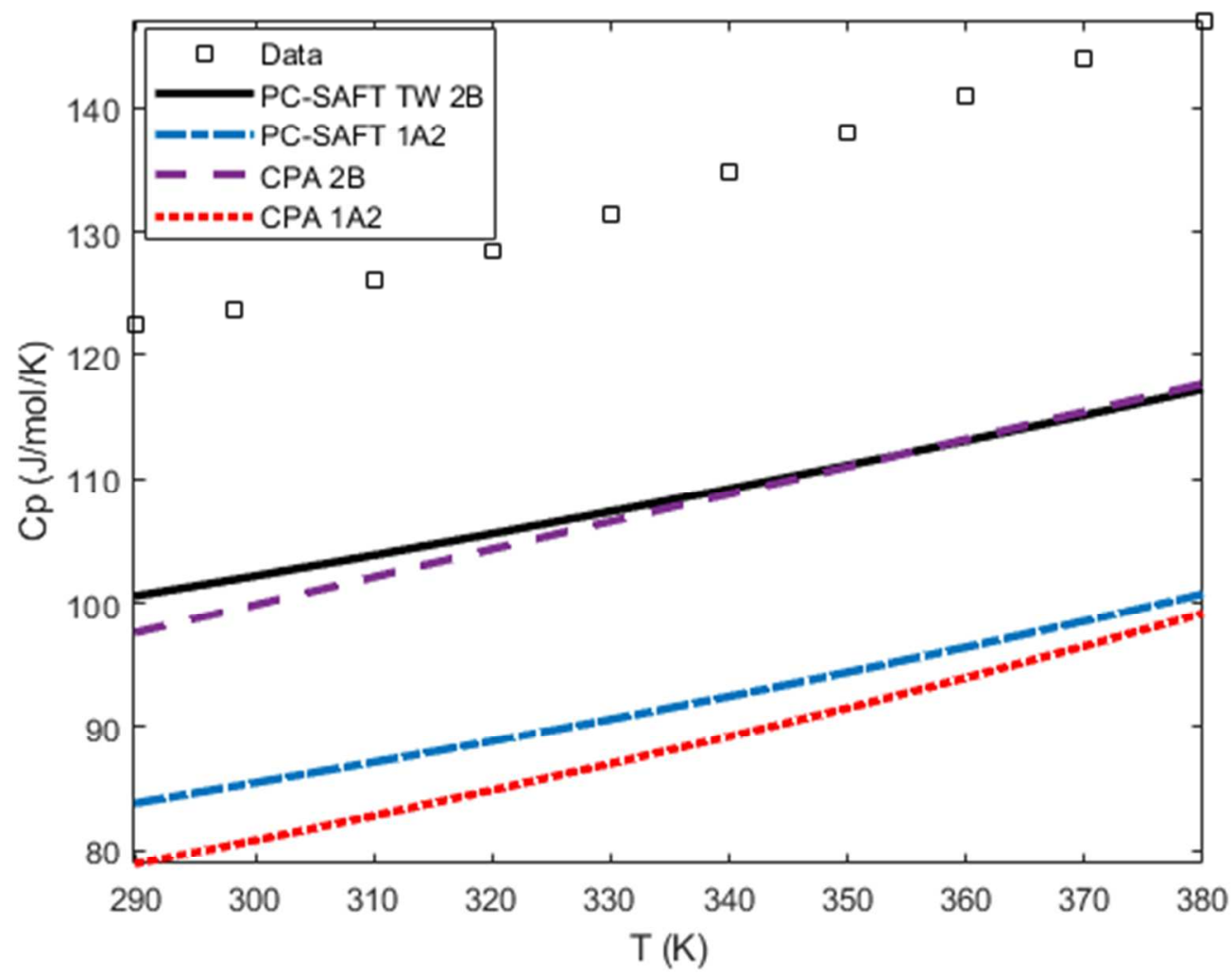

Figure 6. Experimental and calculated $C_{p}$ of acetic acid with SPC-SAFT and CPA using different parameters sets. ( $\square$ ) Data from DIPPR ${ }^{29}$ 


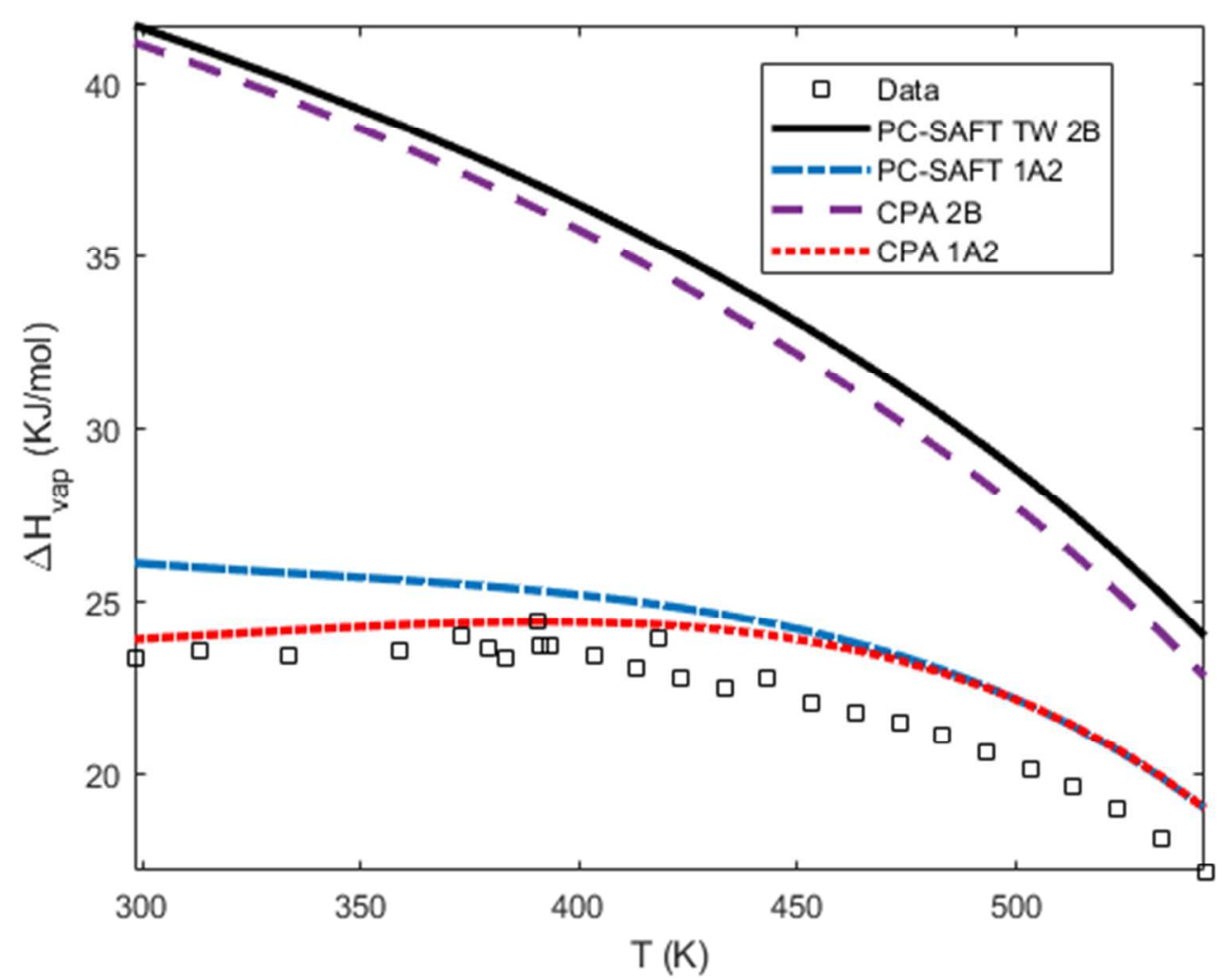

Figure 7. Experimental and calculated enthalpy of vaporization of acetic acid with sPC-SAFT and CPA using different parameters sets. Data are taken from DIPPR ${ }^{29}$ 


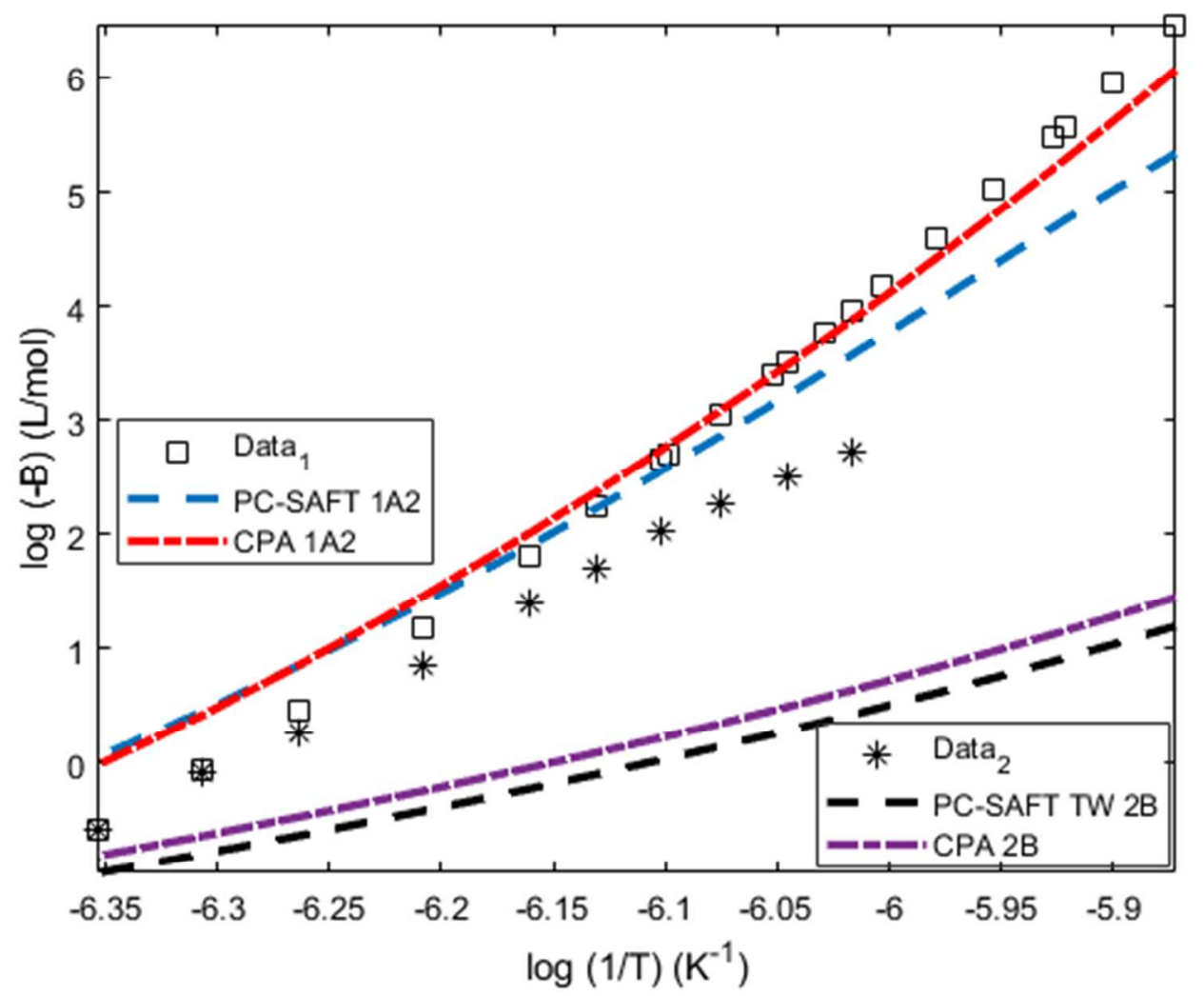

Figure 8. Experimental and calculated second virial coefficient of acetic acid with SPC-SAFT and CPA using different parameters sets. Data 1 taken from $(\square)$ Tsonopoulos and Prausnitz ${ }^{1}$, (*) Data $_{2}$ taken from Bich et al. ${ }^{32}$ 


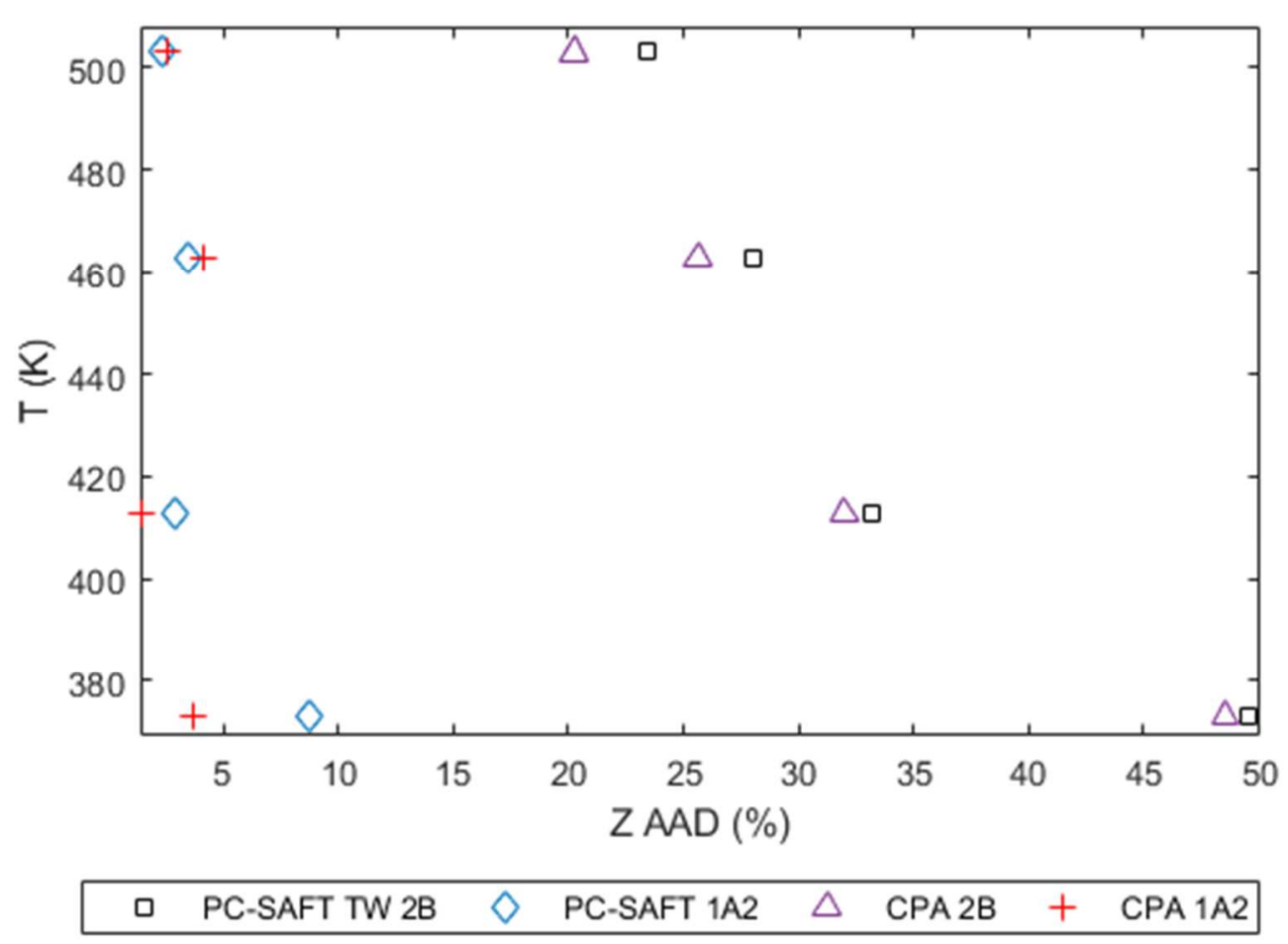

Figure 9. Results of the Average Absolute Deviation (AAD \%) in different temperatures of the compressibility factor of acetic acid with sPC-SAFT and CPA using different parameters sets. 
Binary mixtures. It is important to evaluate the capabilities of a model for phase equilibria. This was done in this work by fitting the phase equilibria data of three binary mixtures (Water Acetic Acid, Hexane - Acetic Acid and Ethanol - Acetic Acid) and using both associating schemes of the acetic acid.

For the mixture with water, three schemes of association that are used for water $(2 \mathrm{~B}, 3 \mathrm{~B}$, 4C) were tested. This was done in order to see if the chosen scheme could influence the optimal results. The results are presented in Figure 10-14 and in Table 6-8.

Water - Acetic Acid. The water parameters were taken from the literature and were named as follows:

- For water using the 2B scheme - PC-SAFT W 2B. ${ }^{45}$

- For water using the $3 \mathrm{~B}$ scheme - PC-SAFT W 3B. ${ }^{45}$

- For water using the $4 \mathrm{C}$ scheme - PC-SAFT W 4C, ${ }^{46} \mathrm{CPA} W 4 \mathrm{C} ;{ }^{47}$

The sets of the acetic acid and water where fitted using the data of Freeman and Wilson ${ }^{33}$ and Nass, available at the Dortmund Data Bank $^{31}$ for the binary mixture phase equilibria. The results are presented in Figure 10-12 and in Table 6. 

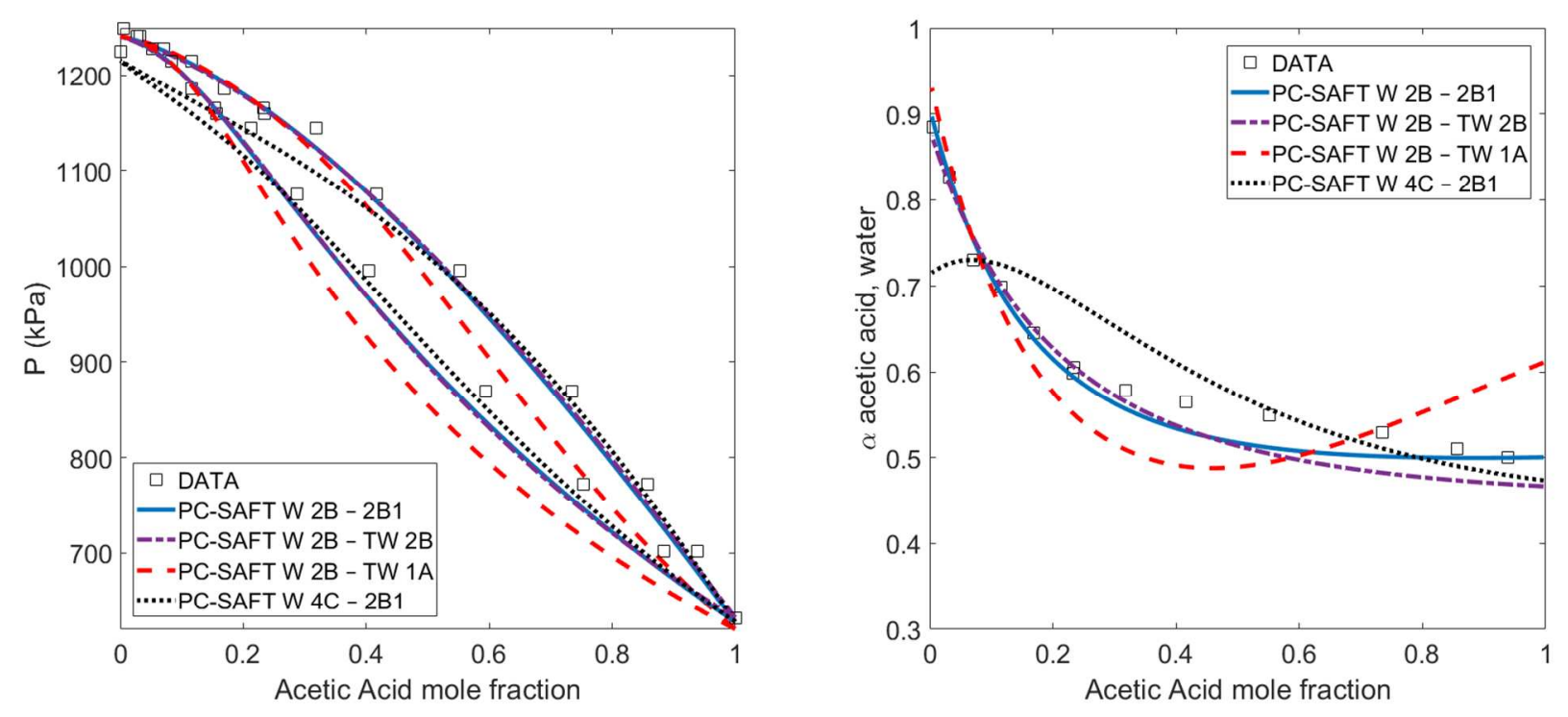

Figure 10. Correlated and experimental results of vapor-liquid equilibria (Left) and acetic acid relative volatility (Right) between acetic acid and water at $462.05 \mathrm{~K}$ using sPC-SAFT. Data are taken from Freeman and Wilson ${ }^{33}$, The $k_{i j}$ values can be found in Table 6 . 
Table 6. Values of the $\Delta P(\%), \Delta y(\%), \Delta \alpha(\%)$ for fitted $k_{i j}$, for water - acetic Acid with sPCSAFT and CPA

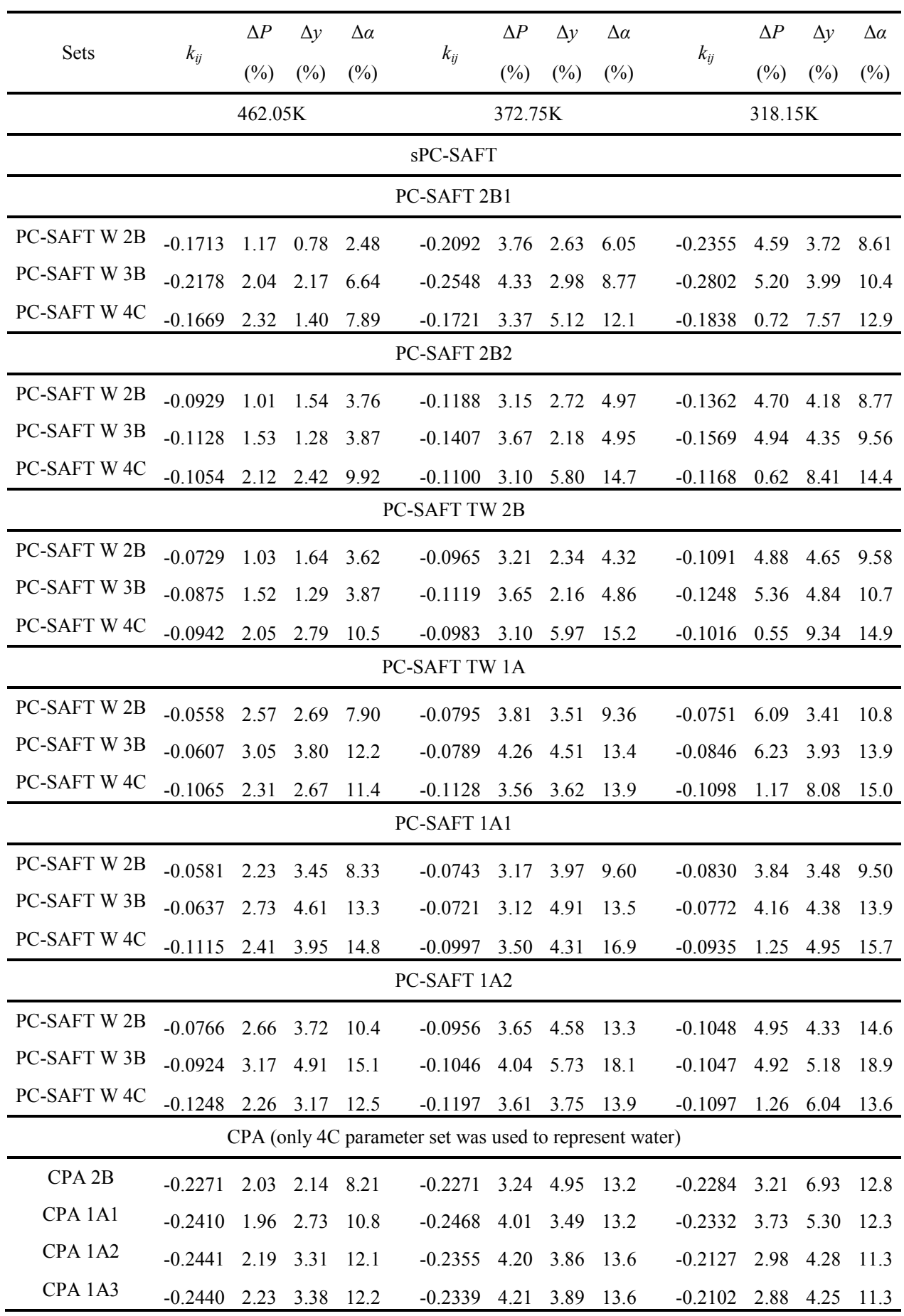


As one can see from Table 6 , at $462.05 \mathrm{~K}$ the smallest total deviations were achieved with sPC-SAFT using the sets PC-SAFT W 2B - PC-SAFT 2B1, followed by PC-SAFT W 2B PC-SAFT TW 2B. Scheme 1A for acetic acid performed poorer than 2B in almost all cases. Using scheme 2B for acetic acid, scheme 4C did not perform as well as scheme $2 \mathrm{~B}$ for water. Analyzing Figure 10 (Right), the experimental data monotonically decreases with increase in acetic acid content, presenting a positive second-order derivative of $\alpha$ with respect to acetic acid mole fraction at low acid concentrations. This behavior was correctly correlated with sPC-SAFT sets PC-SAFT W 2B - PC-SAFT 2B1 and PC-SAFT W 2B - PC-SAFT TW 2B, but the secondorder function derivative was not matched when using scheme $1 \mathrm{~A}$ for acetic acid or $4 \mathrm{C}$ for water.
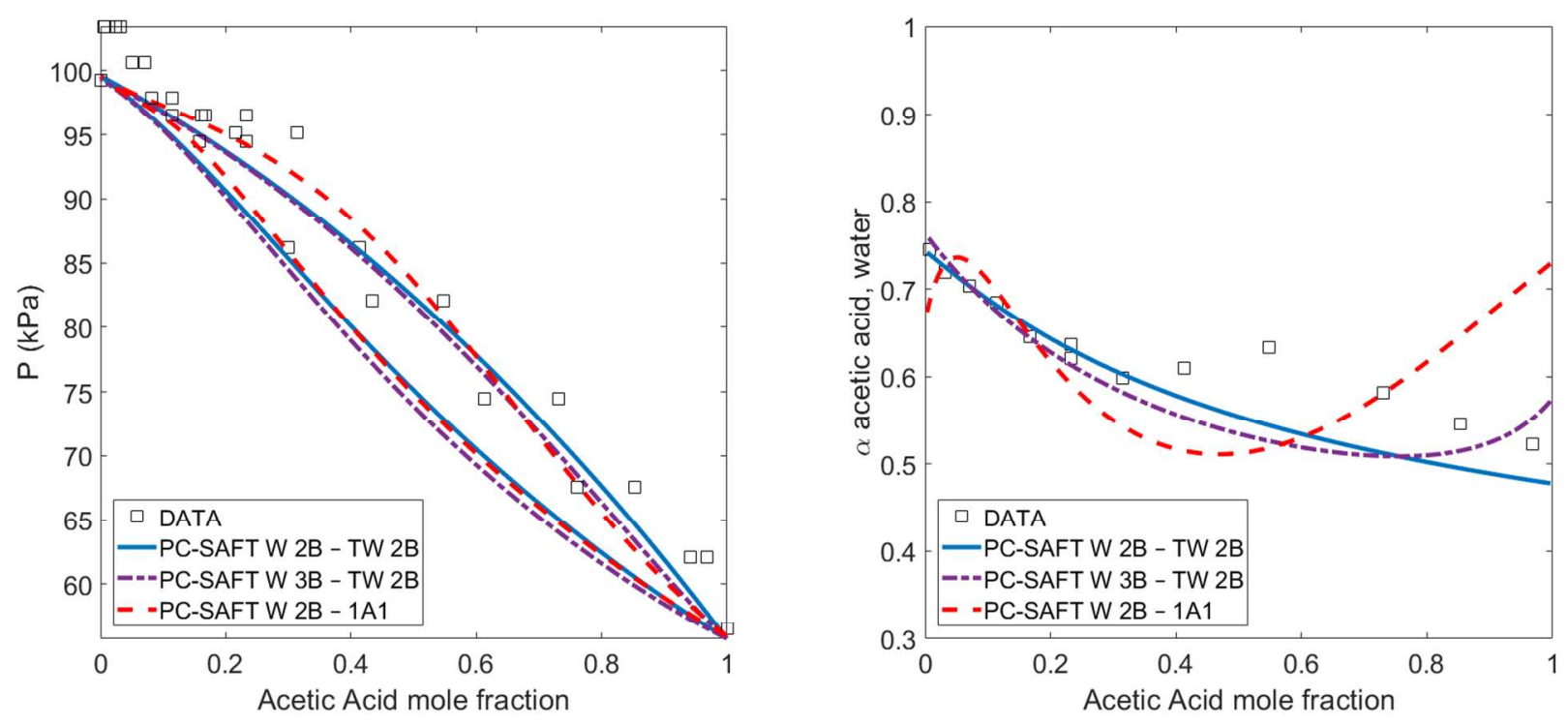

Figure 11. Correlated and experimental results of vapor-liquid equilibria (Left) and acetic acid relative volatility (Right) between acetic acid and water at $372.75 \mathrm{~K}$, using sPC-SAFT. Data are taken from Freeman and Wilson. ${ }^{33}$ The $k_{i j}$ values can be found in Table 6 .

At the temperature $372.75 \mathrm{~K}$, the best results were achieved with the sPC-SAFT sets PCSAFT W 2B - PC-SAFT TW 2B, PC-SAFT W 3B - PC-SAFT TW 2B and by PC-SAFT W 3B PC-SAFT 2B2. Schemes 2B and 1A for acetic acid led to compatible results, with a little advantage to $2 \mathrm{~B}$. Using scheme $1 \mathrm{~A}$ for acetic acid, scheme $4 \mathrm{C}$ performed poorer for water. 
Analyzing Figure 11 (Right), the experimental data in general monotonically decreases with increase in acetic acid content, except at about 0.5 mole fraction, where data increases with acetic acid content. The general behavior is correctly correlated with PC-SAFT W 2B - TW 2B and PC-SAFT W 3B - PC-SAFT TW 2B, and also with the best parameter set for scheme 1A, PC-SAFT W 2B - PC-SAFT TW 1A, although in this case the derivative of $\alpha$ with respect to acetic acid mole fraction at low acid concentrations is lower than that of experimental data. In addition, when one compares the deviations at $462.05 \mathrm{~K}$ with those at $372.75 \mathrm{~K}$, it is clear that the deviations are higher at the lowest temperature.
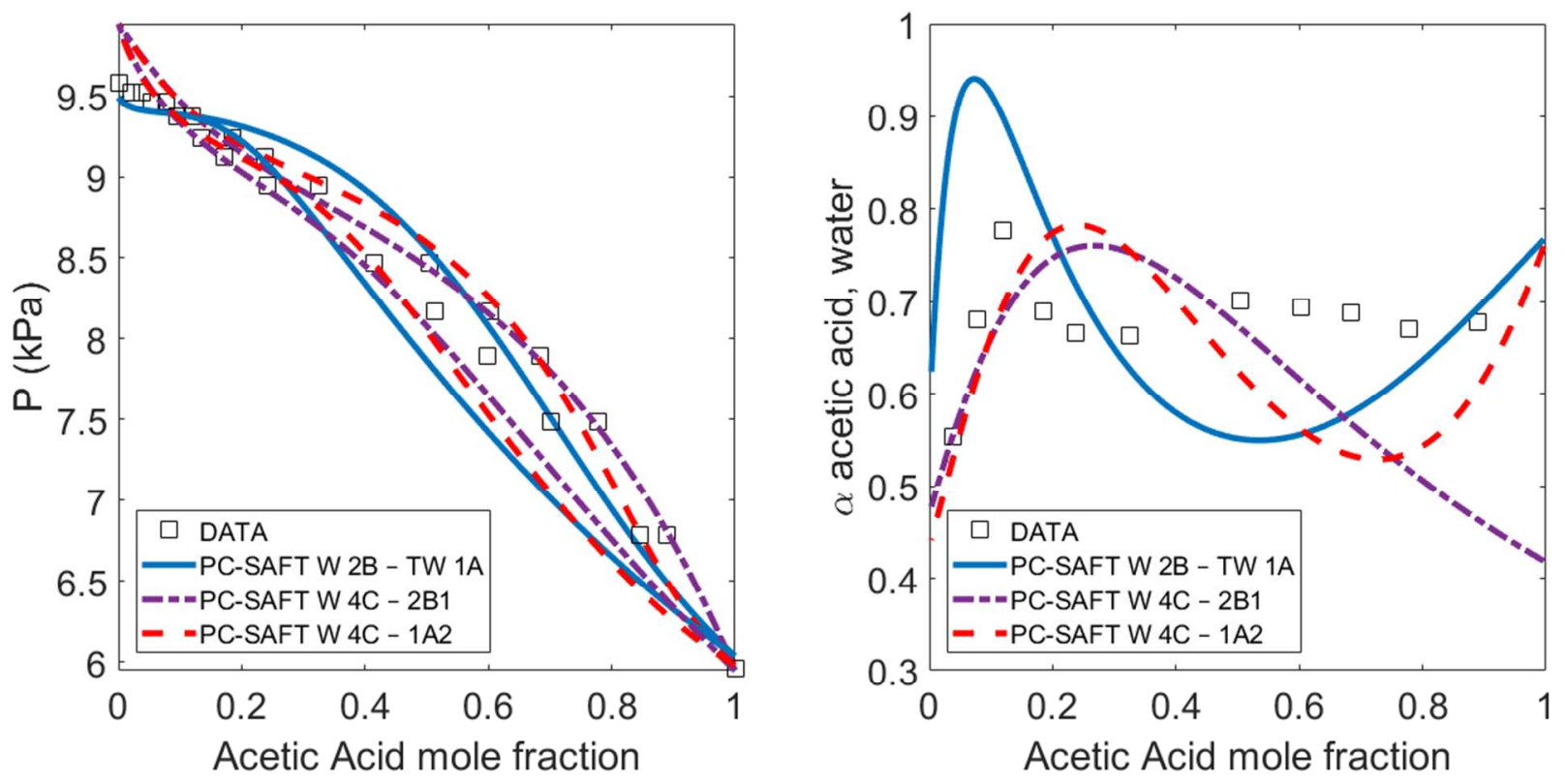

Figure 12. Correlated and experimental results of vapor-liquid equilibria (Left) and acetic acid relative volatility (Right) between acetic acid and water at $318.15 \mathrm{~K}$, using sPC-SAFT. Data are taken from Nass, available at the Dortmund Data Bank. ${ }^{31}$ The $k_{i j}$ values can be found in Table 6 .

At the temperature $318.15 \mathrm{~K}$, the best results based on the total deviation were achieved with the schemes PC-SAFT W 2B - PC-SAFT 1A1, followed by PC-SAFT W 2B - PC-SAFT 2B1 and by PC-SAFT W 2B - PC-SAFT 2B2. Schemes 2B and 1A for acetic acid led to comparable 
results, and results depend more on the parameter set used. Scheme 3B performed poorer for water. Analyzing Figure 12 (Right), the experimental data, in general, scatter a cross a constant, presenting both positive and negative first and second derivative. This behavior was not well correlated by the models, with PC-SAFT W 2B - PC-SAFT 1A1 closer to experimental data. Also, comparing deviations at $318.15 \mathrm{~K}$ with those at 372.75 and $462.05 \mathrm{~K}$, it is clear that the deviations increase as the temperature decreases.

SPC-SAFT and CPA had similar performances in the three temperatures and with the evaluated schemes. From the highest to the lowest studied temperature, the deviations decreased and, while for the water the best association scheme remained the $2 \mathrm{~B}$, for the acetic acid, the chosen association scheme was he 2B scheme. The scheme PC-SAFT TW 2B was among the best performances at the highest temperatures, and PC-SAFT TW 1A performed equivalently to TW $2 \mathrm{~B}$ at the lowest temperature.

Although it was possible to attain low deviations in pressure and composition, the use of the 2B scheme to represent water is not recommended as it is a simplification that does not take in account all the hydrogen bounds that the water can perform (4), furthermore the relative volatility also presented deviations higher than $10 \%$. For this case, the studies presented by Breil et al. ${ }^{17}$ and Tsivintzelis and Kontogeorgis ${ }^{21}$ had better performance, but they used an equation that was specifically developed for the water - acetic acid system, the CPA-HV, and has a necessity of more parameters to correlated with the phase equilibria. The details of this equations can be found elsewhere. ${ }^{16}$ 
Hexane - Acetic Acid. The acetic acid and hexane system was fitted using the data from Miyamoto et al ${ }^{48}$ available at the Dortmund Data Bank $^{31}$ for the phase equilibria. The results are presented in Figure 13 and in Table 7.

Both models performed very similarly, with the $1 \mathrm{~A}$ scheme leading to better correlations, but only CPA and the PC-SAFT 1A set could simulate the shape of the homogeneous azeotrope.
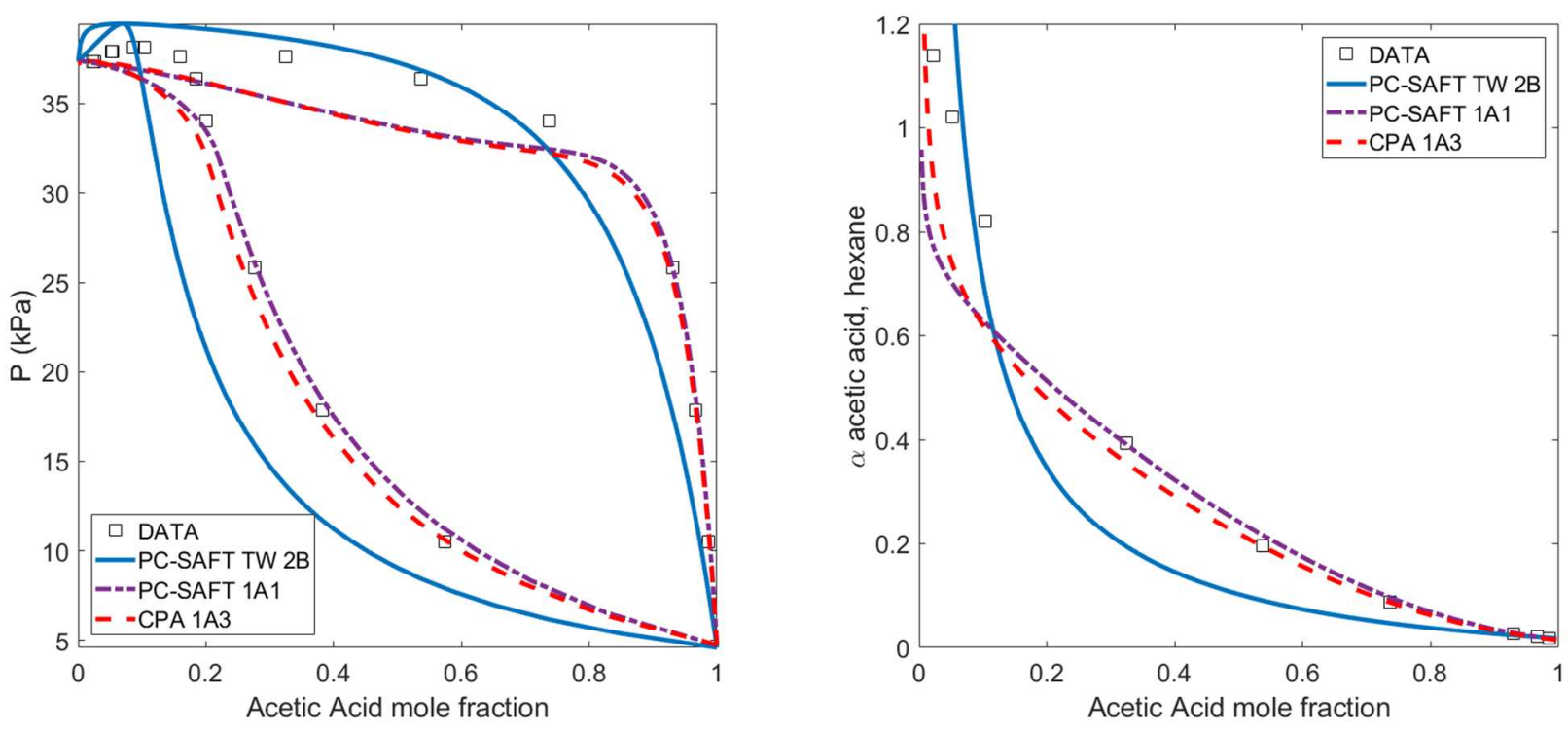

Figure 13. Correlated and experimental behavior of vapor-liquid equilibria (Left) and acetic acid relative volatility (Right) between hexane and acetic acid at $313.2 \mathrm{~K}$ with SPC-SAFT and CPA.

Data are taken from Miyamoto et al, ${ }^{48}$ available at the Dortmund Data Bank, ${ }^{31}$ sPC-SAFT Hexane parameters from Liang et al. ${ }^{34} \mathrm{CPA}$ Hexane parameters from Kontogeorgis et al. ${ }^{14}$ The $k_{i j}$ can be found in Table 7. 
Table 7. Values of the $\Delta P(\%), \Delta y(\%), \Delta \alpha(\%)$ for fitted $k_{i j}$, for hexane - acetic acid at $313.2 \mathrm{~K}$ with sPC-SAFT and CPA

\begin{tabular}{|c|c|c|c|c|c|c|c|c|c|}
\hline Sets & $k_{i j}$ & $\begin{array}{l}\Delta P \\
(\%)\end{array}$ & $\begin{array}{l}\Delta y \\
(\%)\end{array}$ & $\begin{array}{l}\Delta \alpha \\
(\%)\end{array}$ & $\begin{array}{c}\text { Parameter } \\
\text { set }\end{array}$ & $k_{i j}$ & $\begin{array}{l}\Delta P \\
(\%)\end{array}$ & $\begin{array}{c}\Delta y \\
(\%)\end{array}$ & $\begin{array}{l}\Delta \alpha \\
(\%)\end{array}$ \\
\hline \multicolumn{5}{|c|}{ sPC-SAFT } & \multicolumn{5}{|c|}{$\mathrm{CPA}$} \\
\hline \multicolumn{10}{|c|}{ 2B scheme for acetic-acid } \\
\hline PC-SAFT 2B1 & -0.0008 & 12.03 & 4.69 & 46.7 & CPA 2B & -0.0188 & 11.7 & 4.36 & 35.3 \\
\hline PC-SAFT 2B2 & 0.0011 & 12.33 & 4.62 & 41.3 & & & & & \\
\hline PC-SAFT TW 2B & -0.0090 & 12.42 & 4.56 & 37.4 & & & & & \\
\hline \multicolumn{10}{|c|}{ 1A scheme for acetic-acid } \\
\hline PC-SAFT TW 1A & 0.0328 & 5.11 & 7.40 & 27.1 & CPA 1A1 & 0.0591 & 3.63 & 6.04 & 21.20 \\
\hline PC-SAFT 1A1 & 0.0540 & 4.51 & 1.50 & 13.0 & CPA $1 \mathrm{~A} 2$ & 0.0653 & 4.05 & 2.31 & 12.74 \\
\hline PC-SAFT 1A2 & 0.0514 & 4.05 & 3.73 & 17.1 & CPA $1 \mathrm{~A} 3$ & 0.0654 & 4.10 & 2.02 & 12.10 \\
\hline
\end{tabular}

As one can see from Table 7, the best results were achieved with the schemes CPA 1A3, followed by CPA $1 \mathrm{~A} 2$ and by AC 1A1. Scheme 2B for acetic acid performed poorer than 1A in all cases. Analyzing Figure 13 (Right), the experimental data monotonically decreases with increase in acetic acid content, presenting a positive second derivative and starting above 1 and then falling below 1 around 0.05 acetic acid mole fraction. This behavior is correctly correlated with the best parameter sets, and also with the best set for scheme 2B, PC-SAFT TW $2 \mathrm{~B}$. 
Ethanol - Acetic Acid. For ethanol-acetic acid, we have used the data from from Rius et al., ${ }^{49}$ available at the Dortmund Data Bank. ${ }^{31}$ The results are presented in Figure 14 and in Table 8. Once again, both models show similar behavior, with 1A scheme leading to better correlations.
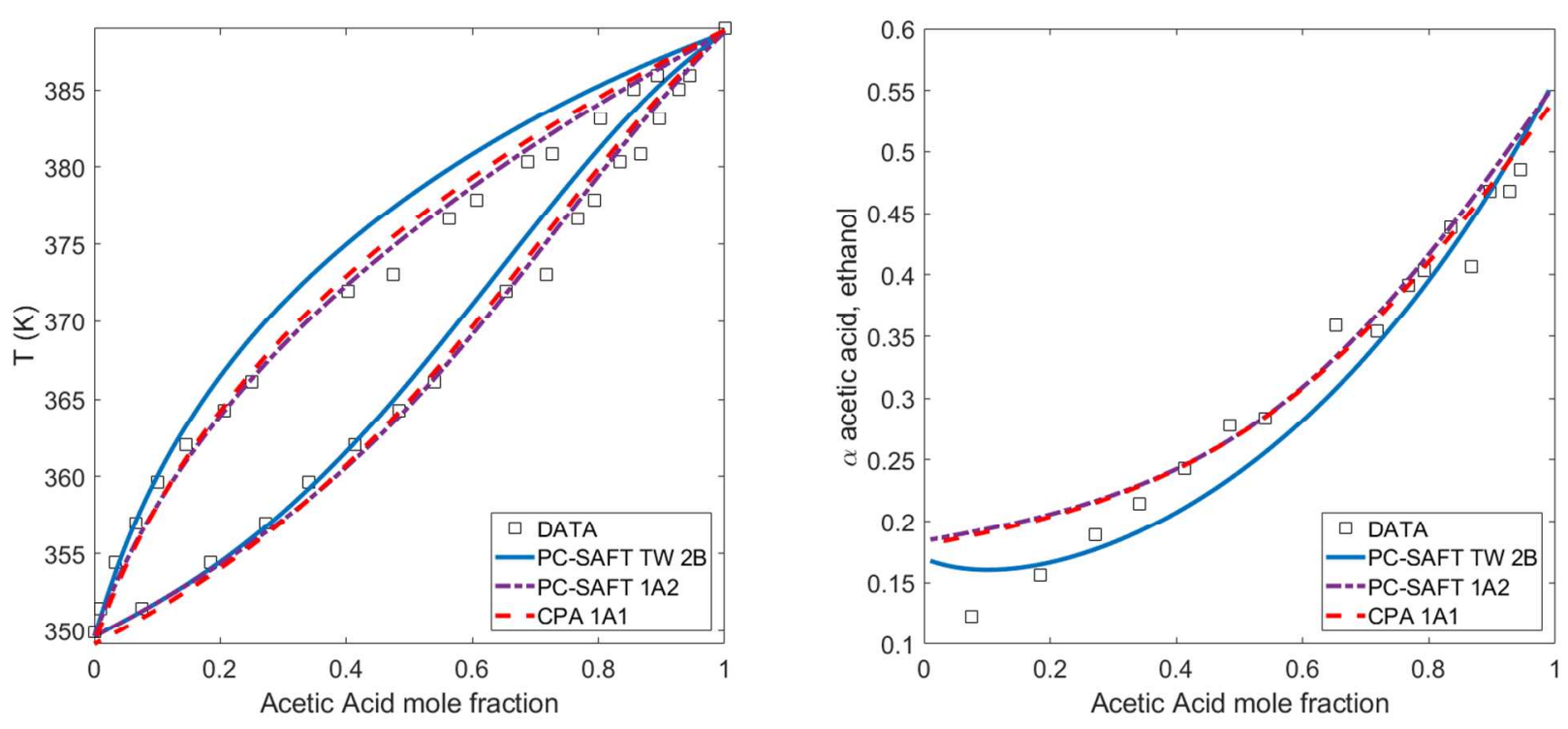

Figure 14. Correlated and experimental behavior of vapor-liquid equilibria (Left) and acetic acid relative volatility (Right) between ethanol and acetic acid at $\mathrm{P}=94 \mathrm{kPa}$ with $\mathrm{SPC}-\mathrm{SAFT}$ and CPA. Data are taken from Rius et al., ${ }^{49}$ available at the Dortmund Data Bank. ${ }^{31}$ sPC-SAFT ethanol parameters from Gross and Sadowski ${ }^{10}$. CPA ethanol parameters from Kontogeorgis et al. ${ }^{14}$ The $k_{i j}$ can be found in Table 8 . 
Table 8. Values of the $\Delta P(\%), \Delta y(\%), \Delta \alpha(\%)$ for fitted $k_{i j}$, for ethanol - acetic acid at $94 \mathrm{kPa}$ with SPC-SAFT and CPA

\begin{tabular}{cccccccccc}
\hline Sets & $k_{i j}$ & $\begin{array}{c}\Delta P \\
(\%)\end{array}$ & $\begin{array}{c}\Delta y \\
(\%)\end{array}$ & $\begin{array}{c}\Delta \alpha \\
(\%)\end{array}$ & $\begin{array}{c}\text { Parameter } \\
\text { set }\end{array}$ & $k_{i j}$ & $\begin{array}{c}\Delta P \\
(\%)\end{array}$ & $\begin{array}{c}\Delta y \\
(\%)\end{array}$ & $\begin{array}{c}\Delta \alpha \\
(\%)\end{array}$ \\
\hline \multicolumn{10}{c}{ CPA } \\
\hline \multicolumn{10}{c}{ 2B scheme for acetic-acid } \\
\hline PC-SAFT 2B1 & -0.0860 & 0.55 & 1.47 & 4.63 & CPA 2B & -0.0968 & 0.47 & 1.41 & 4.19 \\
PC-SAFT 2B2 & -0.0805 & 0.42 & 1.99 & 7.20 & & & & & \\
PC-SAFT TW 2B & -0.0817 & 0.40 & 2.33 & 8.78 \\
\hline \multicolumn{10}{c}{$1 \mathrm{~A}$ scheme for acetic-acid } \\
\hline PC-SAFT TW 1A & -0.0382 & 0.33 & 2.60 & 11.0 & CPA 1A1 & -0.0167 & 0.28 & 1.55 & 8.95 \\
PC-SAFT 1A1 & -0.0029 & 0.22 & 2.34 & 12.3 & CPA 1A2 & -0.0023 & 0.27 & 1.89 & 10.4 \\
PC-SAFT 1A2 & -0.0057 & 0.21 & 1.97 & 9.88 & CPA 1A3 & -0.0004 & 0.26 & 1.88 & 10.5 \\
\hline
\end{tabular}

As one can see from Table 8 , the best results were achieved with the schemes CPA 2B, followed by PC-SAFT 2B1and by CPA 1A1. Scheme 1A for acetic acid performed poorer than 2B in all cases. Analyzing Figure 14 (Right), the experimental data monotonically increases with increase in acetic acid content, linearly to a straight line. This behavior is correctly correlated with the best models for acetic acid mole fraction above 0.5. PC-SAFT TW 2B led to a minimum in this curve, misleading the experimental behavior.

Comparing the results for water, hexane and ethanol, one can see that acetic acid was better represented with scheme $1 \mathrm{~A}$ for pure properties and in mixtures with hexane (at $313.2 \mathrm{~K}$ ) and was satisfactorily well represent as scheme $1 \mathrm{~A}$ with water $(4 \mathrm{C})$ at $318.15 \mathrm{~K}$. Acetic acid was better represented with scheme $2 \mathrm{~B}$ in mixture with water at $372.75 \mathrm{~K}$ and $462.05 \mathrm{~K}$, but water had to be represented by schemes $3 \mathrm{~B}$ and $2 \mathrm{~B}$. The need for changing the association scheme of water shows the complexity of this system, and it is the probable cause of change from $1 \mathrm{~A}$ to $2 \mathrm{~B}$ the best association scheme for acetic acid. 


\section{DISCUSSION}

For the acetic acid, the best overall correlation of properties of liquid phase and vapor pressure were obtained with the parameter sets presented in this work, with deviations below $1.5 \%$ for vapor pressure, liquid density and liquid speed of sound. Also, the lowest deviations for liquid heat capacity were obtained with the parameters presented in this work.

As previously shown ${ }^{8-20}$, the Wertheim theory ${ }^{4-7}$ has been used with some success for predicting a few of the acetic acid pure component properties, especially vapor pressure and density, but it was not successful in predicting the various derivative properties where it has not been extensively used either. This is also supported by the findings of Kontogeorgis, ${ }^{50}$ where the author summarizes some comparative studies focusing on association theories with different frameworks to predict the derivative properties (e.g. Cp, $\mathrm{Cv}$, speed of sound).

At this stage, it is of interest and for comparison to the present work to summarize some related studies also for aqueous acetic acid mixtures. The Wertheim theory has been used in diverse frameworks for correlating phase equilibria data of acetic acid mixtures, especially with water.

Fu and Sandler ${ }^{9}$ proposed a simplified SAFT (sSAFT) equation. The authors substitute the dispersion term implemented by Huang and Radosz in the SAFT equation ${ }^{8}$ with a single attraction term for the square-well fluid. They show in their work that sSAFT and SAFT are not able to obtain good correlations for the acetic acid and water phase equilibria.

It is clear from these results (from literature and from this work) that the association theory has some limitations. For example, the Wertheim theory does not consider the possibility of differences between the hydrogen bonds, neither the formation of cyclic structures nor the presence of intramolecular association,,$^{22,23,27,50-54}$ and because of these limitations some suggestions for changes have been proposed in the literature.

Muro-Suñé et al. ${ }^{16}$ studied the water (4C) and acetic acid (1A) phase equilibria using CPA. After trying to improve the correlation using several methods without success, they modified the mixing rule of the energy parameter by using the Huron-Vidal mixing rule together with a modified non-random two-liquid (NRTL) equation instead of the van der Waals one-fluid mixing 
rule and they were able to obtain a satisfactory correlation at the cost of more adjustable parameters.

This Huron-Vidal modification of CPA was later studied by Breil et al., ${ }^{17}$ Kontogeorgis and Folas $^{27}$ and Tsivintzelis and Kontogeorgis ${ }^{21}$. Breil et al. ${ }^{17}$ and Kontogeorgis and Folas ${ }^{27}$ applied the CPA EOS with the Huron-Vidal mixing rule ${ }^{16}$ to correlate the water (4C) and acetic acid (1A) phase equilibria. They fitted the parameters for the Huron-Vidal mixing rule using the relative volatility data of acetic acid and water. The authors were able to obtain excellent correlation results, but they were not able to use only one set of parameters to describe the whole range of the temperatures studied, and they recommended the use of different sets, one for temperatures below $373 \mathrm{~K}$, and one for higher temperatures.

Tsivintzelis and Kontogeorgis ${ }^{21}$, using the same sets for pure acetic acid parameters as proposed by Breil et al., ${ }^{17}$ investigated if including infinite dilution and/or vapor compressibility data of the phase equilibria together with the relative volatility data of acetic acid and water during the estimation of the parameters for the Huron-Vidal mixing rule could lead to a better correlation of the phase equilibria. The findings of Tsivintzelis and Kontogeorgis ${ }^{21}$ were in agreement to those by Breil et al. ${ }^{17}$ and Kontogeorgis and Folas. ${ }^{27}$ They obtained excellent correlation results for phase equilibria and they also noticed the need of more than one parameter sets to describe the phase equilibria over an extensive temperature range.

A different approach was followed by Janeček and Paricaud ${ }^{22,23}$ and Sum and Sandler. ${ }^{24}$ Sum and Sandler $^{24}$ proposed a modification of the UNIQUAC model to include the Wertheim theory using parameters obtained from ab initio quantum mechanics calculations, but the authors did not get good results when they tried to correlate the phase equilibria of water and acetic acid. Janeček and Paricaud ${ }^{22,23}$ correlated the water (4C) and acetic acid (2B) phase equilibria with a modified PC-SAFT, named PC-SAFT-DBD. ${ }^{22,23}$. This modification is based on the work of Sear and Jackson ${ }^{52}$, that extended the classical $2 \mathrm{~B}$ association model $^{8}$ to take in account the formation of cyclic dimers, and includes one term and one more adjustable parameter to the expression for the association contribution used in PC-SAFT. They compared the results of the new implementation with the standard PC-SAFT model. In their work, they limit the formation of cyclic dimers to the acetic acid, not allowing that the water molecule nor the hydroxyl group form a cyclic association with the carboxyl group. Both models have similar performance 
correlating the phase equilibria, presenting low deviations in pressure and in the vapor composition using large negative values (closer to -1) for the binary interaction parameter. Unfortunately, Janeček and Paricaud, ${ }^{23}$ did not provide information about the relative volatility of the acetic acid-water systems they tested and, as can be observed from the results of Tables 68 , the relative volatility is an important sensitive property in order to truly evaluate the model correlation performance for the water - acetic acid phase equilibria. We see the same problem in numerous other studies with SAFT models like the one mentioned before by Fu and Sandler ${ }^{9}$ and also Kouskoumvekaki et al. ${ }^{11}$ and Wolbach and Sandler; ${ }^{3}$ i.e. VLE results are presented for water-acetic acid in Pxy or Txy plots. Such plots are very much deceiving for this mixture and without presenting detailed results in form of relative volatilities over extended temperature ranges it is difficult to appropriately assess the model performance.

We summarized some of the results previously presented in literature in Table 9. 
Table 9. Summary of some literature correlation results for the acetic acid-water mixture compared also to selected results from this work

\begin{tabular}{|c|c|c|c|c|c|}
\hline Model & & $k_{i j}$ & $\begin{array}{l}\Delta P \\
(\%)\end{array}$ & $\begin{array}{l}\Delta y \\
(\%)\end{array}$ & $\begin{array}{l}\Delta \alpha \\
(\%)\end{array}$ \\
\hline $\operatorname{SAFT}(2 \mathrm{~B}-4 \mathrm{C})^{\mathrm{a}}$ & $\mathrm{T}=372.75 \mathrm{~K}$ & 0.2335 & 2.9 & - & 106 \\
\hline Or. PC-SAFT (2B-2B) ${ }^{a}$ & & -0.1221 & 3.7 & - & 5.9 \\
\hline PC-SAFT (2B-4C) $)^{\mathrm{a}}$ & & -0.0228 & 4.4 & - & 24.6 \\
\hline PC-SAFT (2B-4C) ${ }^{\mathrm{a}}$ & & -0.15 & 2.1 & - & 21.8 \\
\hline PC-SAFT (2B-2B) ${ }^{\mathrm{a}}$ & & -0.08 & 2.9 & - & 16.5 \\
\hline CPA - HV $(1 \mathrm{~A}-4 \mathrm{C})^{\mathrm{a}}$ & & - & 4 & 0.3 & 2.4 \\
\hline CPA - HV (1A-4C) $)^{\mathrm{b}}$ & & - & - & - & 3.8 \\
\hline CPA - HV $(1 \mathrm{~A}-4 \mathrm{C})^{\mathrm{c}}$ & & - & - & - & 1.9 \\
\hline sPC-SAFT (2B-2B) ${ }^{\mathrm{d}}$ & & -0.0965 & 3.2 & 2.7 & 4.9 \\
\hline sPC-SAFT (1A-2B) ${ }^{\mathrm{d}}$ & & -0.0795 & 3.8 & 3.5 & 9.3 \\
\hline $\mathrm{CPA}(2 \mathrm{~B}-4 \mathrm{C})^{\mathrm{d}}$ & & -0.2271 & 3.2 & 4.9 & 13.2 \\
\hline Or. PC-SAFT (2B-4C) ${ }^{\mathrm{a}}$ & $\mathrm{T}=462.05 \mathrm{~K}$ & -0.0896 & 1.4 & - & 3.3 \\
\hline PC-SAFT $(2 B-4 C)^{a}$ & & 0.0091 & 2.5 & - & 17.1 \\
\hline PC-SAFT $(2 B-4 C)^{\mathrm{a}}$ & & -0.15 & 1 & - & 9.8 \\
\hline PC-SAFT (2B-2B) ${ }^{\mathrm{a}}$ & & -0.08 & 2.4 & - & 4 \\
\hline $\mathrm{CPA}-\mathrm{HV}(1 \mathrm{~A}-4 \mathrm{C})^{\mathrm{a}}$ & & - & 1.5 & 0.4 & 4.3 \\
\hline CPA - HV $(1 \mathrm{~A}-4 \mathrm{C})^{\mathrm{b}}$ & & - & - & - & 12.3 \\
\hline $\mathrm{CPA}-\mathrm{HV}(1 \mathrm{~A}-4 \mathrm{C})^{\mathrm{c}}$ & & - & - & - & 12 \\
\hline sPC-SAFT (1A-2B) & & -0.0558 & 2.6 & 2.7 & 7.9 \\
\hline sPC-SAFT (2B-2B) ${ }^{\mathrm{d}}$ & & -0.0729 & 1.0 & 1.6 & 3.6 \\
\hline CPA $(2 B-4 C)^{d}$ & & -0.2271 & 2.0 & 2.1 & 8.11 \\
\hline PC-SAFT(DBD-4C) ${ }^{\mathrm{e}}$ & $\mathrm{P}=101.3 \mathrm{Kpa}$ & -0.1178 & 1.3 & 0.9 & - \\
\hline Or. PC-SAFT(2B-4C) ${ }^{e}$ & & -0.1472 & 0.9 & 1.6 & - \\
\hline PC-SAFT(DBD-4C) ${ }^{\mathrm{e}}$ & $\mathrm{P}=26.67 \mathrm{Kpa}$ & -0.1148 & 2.1 & 1.2 & - \\
\hline Or. PC-SAFT(2B-4C) ${ }^{\mathrm{e}}$ & & -0.1404 & 2.2 & 2.4 & - \\
\hline PC-SAFT(DBD-4C) ${ }^{\mathrm{e}}$ & $\mathrm{P}=9.33 \mathrm{Kpa}$ & -0.1154 & 1.9 & 1.4 & - \\
\hline Or. PC-SAFT(2B-4C) ${ }^{\mathrm{e}}$ & & -0.1454 & 2 & 2.3 & - \\
\hline
\end{tabular}

${ }^{\mathrm{a}}$ Results from Kontogeorgis and Folas $(2010)^{27} ;{ }^{\mathrm{b}}$ Results from Breil. et al $(2011)^{17} ;{ }^{\mathrm{c}}$ Results from Tsivintzelis and Kontogeorgis $(2014)^{21} ;{ }^{\mathrm{d}}$ Results from this work; ${ }^{\mathrm{e}}$ Results from Janeček and Paricaud (2013);

Analyzing the results from Table 9 we conclude that the performance of sPC-SAFT and CPA is not satisfactory for correlating the acetic acid - water mixture. Different combination of association schemes were tried and both models needed large values for the binary interaction parameter and can not provide an accurate description of the relative volatility. In this scenario, sPC-SAFT had the best performance using the $2 \mathrm{~B}$ scheme for both compounds. The performance 
of CPA improves when the Huron-Vidal mixing rule is used for the correlation, but this came with a cost of more parameters and it was not possible to use only one set of parameters to describe the whole extension of temperatures studied. With only the results provided by Janeček and Paricaud ${ }^{23}$, it is not possible to say that his modification can provide better correlations than sPC-SAFT as both model have comparable performance correlating the phase equilibria and it is still necessary to use a large negative binary interaction parameter.

In conclusion, it is possible to have a qualitative correlation for the pure component properties of acetic acid and phase equilibria of water and acetic acid. However, to achieve quantitative results and for both phase equilibria and a wide range of properties including derivatives ones, modifications on these models addressing some of the limitations of the Wertheim theory are required. The ultimate test of all approaches should be, on one hand, the accurate representation of various pure acetic acid properties over extensive conditions, binary mixtures with water (and other compounds) and last but not least the prediction of ternary and in general multicomponent VLE and LLE of acetic acid-containing mixtures (with water, alkanes, $\mathrm{CO} 2$, etc). 


\section{CONCLUSIONS}

In this work, we have evaluated the capabilities of the SPC-SAFT and CPA EoS for representing an extensive range of properties for acetic acid and its mixtures.

Both equations of state can describe well the behavior of the vapor pressure and the density (293 - $543 \mathrm{~K})$ of the acetic acid using the two association schemes considered, 1A and 2B, with the 2B scheme performing slightly better for these two properties. None of the models describes very well the isobaric heat capacity, with CPA presenting lower deviations when used with the 1A scheme.

sPC-SAFT was not able to describe accurately the compressibility factor of the vapor phase and the enthalpy of vaporization, especially at low temperatures. This behavior was also observed when using the $2 \mathrm{~B}$ scheme in CPA.

The correlation of the phase equilibria using SPC-SAFT and CPA also presented a rather similar picture with the two models. Both equations of state cannot provide an accurate description of the relative volatility for water-acetic acid mixtures and, except for the phase equilibria with water, the $1 \mathrm{~A}$ scheme performed better.

Overall, the 1A scheme had the best performance to correlate all the properties of the acetic acid, but more than one parameter set is required to describe all the pure properties or the phase equilibria in a wide temperature range.

Acetic acid can form dimers and even have an intramolecular association. ${ }^{54}$ The results may indicate that the association theory proposed by Wertheim is not adequate for predicting all the pure properties of acetic acid and for accurately correlating its mixture with water, as the Wertheim theory does not consider the possibility of differences between the hydrogen bonds, neither the formation of cyclic structures nor the presence of intramolecular association. ${ }^{22,23,27,50-}$ 53

New developments focusing in having a better description of the interactions of associating compounds are needed, and although there is some development being done, it is still early to 
say whether a single association scheme or thermodynamic model in general will be able to describe accurately all the properties of acetic acid.

\section{ACKNOWLEDGEMENTS}

The authors acknowledge FAPERJ, CNPq and CAPES for the financial support (PDSE - Process number: 88881.135572/2016-01). 
List of Symbols

\begin{tabular}{|c|c|c|}
\hline $\begin{array}{l}a \\
\mathrm{a}_{0}\end{array}$ & $\begin{array}{l}\text { contribution of the Helmholtz free energy } \\
\text { energy parameter }\end{array}$ & bar $\mathrm{L}^{2} \mathrm{~mol}^{-2}$ \\
\hline $\mathrm{A}_{\mathrm{i}}$ & site $\mathrm{A}$ in molecule $\mathrm{i}$ & - \\
\hline$B$ & second virial coefficient & $\mathrm{L} \mathrm{mol}^{-1}$ \\
\hline $\mathrm{b}$ & co-volume & $\mathrm{L} \mathrm{mol}^{-1}$ \\
\hline$B_{j}$ & site $B$ in molecule $\mathrm{j}$ & - \\
\hline$C p$ & isobaric heat capacity & - \\
\hline CPA 1 A 1 & CPA parameter set & $\mathrm{J} / \mathrm{mol} / \mathrm{K}$ \\
\hline CPA 1 A2 & CPA parameter set & - \\
\hline CPA 1 A3 & CPA parameter set & - \\
\hline CPA 2B & CPA parameter set & - \\
\hline $\mathrm{d}$ & segment diameter & - \\
\hline g & radial distribution function & $\AA$ \\
\hline Hvap & enthalpy of vaporization & - \\
\hline$K_{2}$ & dimerization constant & $\mathrm{KJ} / \mathrm{mol}$ \\
\hline $\mathrm{k}_{\mathrm{ij}}$ & binary interaction parameter & $\mathrm{mmHg}^{-1}$ \\
\hline $\mathrm{m}$ & segment number & - \\
\hline$M_{i}$ & number of association sites of molecule $i$ & - \\
\hline $\mathrm{N}$ & number of experimental points & - \\
\hline $\mathrm{Ni}$ & number of interactions & - \\
\hline $\mathrm{Np}$ & number of particles & - \\
\hline$P$ & pressure & - \\
\hline$P_{S}$ & saturated pressure & $\mathrm{Pa}$ \\
\hline PC-SAFT 1A1 & PC-SAFT parameter set & $\mathrm{Pa}$ \\
\hline PC-SAFT 1A2 & PC-SAFT parameter set & - \\
\hline PC-SAFT 2B1 & PC-SAFT parameter set & - \\
\hline PC-SAFT 2B2 & PC-SAFT parameter set & - \\
\hline PC-SAFT TW 1A & PC-SAFT parameter set & - \\
\hline PC-SAFT TW 2B & PC-SAFT parameter set & - \\
\hline $\mathrm{R}$ & gas constant & - \\
\hline $\mathrm{T}$ & temperature & \\
\hline$u$ & speed of sound & $\mathrm{K}$ \\
\hline $\mathrm{Vm}$ & molar volume & $\mathrm{m} / \mathrm{s}$ \\
\hline $\mathrm{X}$ & monomer fraction & $\mathrm{m}^{3} / \mathrm{mol}$ \\
\hline$x_{i}$ & liquid molar fraction & - \\
\hline $\mathrm{y}$ & vapor molar fraction & - \\
\hline$Z$ & compressibility factor & - \\
\hline
\end{tabular}


List of abbreviations

$\begin{array}{ll}\text { AAD } & \begin{array}{l}\text { average absolute deviation } \\ \text { average }\end{array} \\ \text { CPA } & \text { cubic plus association } \\ \text { EOS } & \text { equation of state } \\ \text { LLE } & \text { liquid-liquid equilibria } \\ \text { ObjF } & \text { objective function } \\ \text { PC-SAFT } & \text { perturbed chain-statistical associating fluid theory } \\ \text { PSO } & \text { particle swarm optimization } \\ \text { SLE } & \text { solid-liquid equilibria } \\ \text { SPC-SAFT } & \text { simplified perturbed chain-statistical associating fluid theory } \\ \text { VLE } & \text { vapor-liquid equilibria }\end{array}$

Greek letters

$\begin{array}{lll}\rho & \text { molar density } & \mathrm{kmol} / \mathrm{m}^{3} \\ \alpha & \text { relative volatility } & - \\ \beta^{\mathrm{AB}} & \text { association volume } & - \\ \Delta^{\mathrm{AB}} & \text { association strength } & - \\ \phi & \text { binary variable } & - \\ \eta & \text { reduced density } & - \\ \kappa^{\mathrm{AB}} & \text { association volume } & - \\ \theta & \text { evaluated property } & - \\ \sigma & \text { segment energy } & \AA \\ \epsilon / \kappa & \text { association energy } & \mathrm{K}\end{array}$

Superscript/Subscripts

$\mathrm{r}$

reduced

chain

hs

chain formation

disp

hard sphere

assoc

$\exp$

calc

id

dispersion forces

association

experimental

calculated

ideal 


\section{REFERENCES}

(1) Tsonopoulos, C.; Prausnitz, J. M. Fugacity Coefficients in Vapor-Phase Mixtures of Water and Carboxylic Acids. Chem. Eng. J. 1970, 1 (4), 273.

(2) Johnson, E. W.; Nash, L. K. The Vapor-Phase Association of Acetic and Trimethylacetic Acids. J. Am. Chem. Soc. 1950, 72 (1), 547.

(3) Wolbach, J. P.; Sandler, S. I. Using Molecular Orbital Calculations To Describe the Phase Behavior of Cross-Associating Mixtures. Ind. Eng. Chem. Res. 1998, 37 (8), 2917.

(4) Wertheim, M. S. Fluids with Highly Directional Attractive Forces. I. Statistical Thermodynamics. J. Stat. Phys. 1984, 35 (1-2), 19.

(5) Wertheim, M. S. Fluids with Highly Directional Attractive Forces. II. Thermodynamic Perturbation Theory and Integral Equations. J. Stat. Phys. 1984, 35 (1-2), 35.

(6) Wertheim, M. S. Fluids with Highly Directional Attractive Forces. III. Multiple Attraction Sites. J. Stat. Phys. 1986, 42 (3-4), 459.

(7) Wertheim, M. S. Fluids with Highly Directional Attractive Forces. IV. Equilibrium Polymerization. J. Stat. Phys. 1986, 42 (3-4), 477.

(8) Huang, S. H.; Radosz, M. Equation of State for Small, Large, Polydisperse and Associating Molecules. Ind. Eng. Chem. Res. 1990, 29, 2284.

(9) Fu, Y.-H.; Sandler, S. I. A Simplified SAFT Equation of State for Associating Compounds and Mixtures. Ind. Eng. Chem. Res. 1995, 34, 1897.

(10) Gross, J.; Sadowski, G. Application of the Perturbed-Chain SAFT Equation of State to Associating Systems. Ind. Eng. Chem. Res. 2002, 41 (22), 5510.

(11) Kouskoumvekaki, I. A.; Krooshof, G. J. P.; Michelsen, M. L.; Kontogeorgis, G. M. Application of the Simplified PC-SAFT Equation of State to the Vapor-Liquid Equilibria of Binary and Ternary Mixtures of Polyamide 6 with Several Solvents. Ind. Eng. Chem. Res. 2004, 43 (3), 826.

(12) Derawi, S. O.; Zeuthen, J.; Michelsen, M. L.; Stenby, E. H.; Kontogeorgis, G. M. Application of the CPA Equation of State to Organic Acids. Fluid Phase Equilib. 2004, 
$225(1-2), 107$.

(13) Folas, G. K.; Kontogeorgis, G. M.; Michelsen, M. L.; Stenby, E. H. Application of the Cubic-plus-Association (CPA) Equation of State to Complex Mixtures with Aromatic Hydrocarbons. Ind. Eng. Chem. Res. 2006, 45 (4), 1527.

(14) Kontogeorgis, G. M.; Michelsen, M. L.; Folas, G. K.; Derawi, S.; Von Solms, N.; Stenby, E. H. Ten Years with the CPA (Cubic-Plus-Association) Equation of State. Part 2. CrossAssociating and Multicomponent Systems. Ind. Eng. Chem. Res. 2006, 45 (14), 4869.

(15) Grenner, A.; Tsivintzelis, I.; Economou, I. G.; Panayiotou, C.; Kontogeorgis, G. M. Evaluation of the Nonrandom Hydrogen Bonding (NRHB) Theory and the Simplified Perturbed-Chain-Statistical Associating Fluid Theory (sPC-SAFT). 1. Vapor-Liquid Equilibria. Ind. Eng. Chem. Res. 2008, 47 (15), 5636.

(16) Muro-Suñé, N.; Kontogeorgis, G. M.; Solms, N. Von; Michelsen, M. L. Phase Equilibrium Modelling for Mixtures with Acetic Acid Using an Association Equation of State. Ind. Eng. Chem. Res. 2008, 47 (15), 5660.

(17) Breil, M. P.; Kontogeorgis, G. M.; Behrens, P. K.; Michelsen, M. L. Modeling of the Thermodynamics of the Acetic Acid-Water Mixture Using the Cubic-plus-Association Equation of State. Ind. Eng. Chem. Res. 2011, 50 (9), 5795.

(18) Soo, C.-B. Experimental Thermodynamic Measurements of Biofuel-Related Associating Compounds and Modeling Using the PC-SAFT Equation of State, École Nationale Supérieure des Mines de Paris, 2011.

(19) Tsivintzelis, I.; Kontogeorgis, G. M. Capabilities and Limitations of an Association Theory for Chemicals in Liquid or Supercritical Solvents. Ind. Eng. Chem. Res. 2012, 51 (41), 13496.

(20) Yushu, C.; Afef, A.; Fabrice, M.; Roland, S.; Jeday, M. R. Thermodynamic Modeling of Mixtures Containing Carboxylic Acids Using the PC-SAFT Equation of State. Ind. Eng. Chem. Res. 2012, 51 (42).

(21) Tsivintzelis, I.; Kontogeorgis, G. M. On the Predictive Capabilities of CPA for Applications in the Chemical Industry: Multicomponent Mixtures Containing Methyl- 
Methacrylate, Dimethyl-Ether or Acetic Acid. Chem. Eng. Res. Des. 2014, 92 (12), 1947.

(22) Janeček, J.; Paricaud, P. Influence of Cyclic Dimer Formation on the Phase Behavior of Carboxylic Acids. J. Phys. Chem. B 2012, 116 (27), 7874.

(23) Janeček, J.; Paricaud, P. Influence of Cyclic Dimer Formation on the Phase Behavior of Carboxylic Acids. II. Cross-Associating Systems. J. Phys. Chem. B 2013, 117 (32), 9430.

(24) Sum, A. K.; Sandler, S. I. A Novel Approach to Phase Equilibria Predictions Using Ab Initio Methods. Ind. Eng. Chem. Res. 1999, 38 (4), 2849.

(25) Gross, J.; Sadowski, G. Perturbed-Chain SAFT: An Equation of State Based on a Perturbation Theory for Chain Molecules. Ind. Eng. Chem. Res. 2001, 40 (4), 1244.

(26) von Solms, N.; Michelsen, M. L.; Kontogeorgis, G. M. Computational and Physical Performance of a Modified PC-SAFT Equation of State for Highly Asymmetric and Associating Mixtures. Ind. Eng. Chem. Res. 2003, 42 (5), 1098.

(27) Kontogeorgis, G. M.; Folas, G. K. Industrial Applications Thermodynamic Models for Industrial Applications From Classical and Advanced; Wiley, 2010.

(28) Kontogeorgis, G. M.; Voutsas, E. C.; Yakoumis, I. V.; Tassios, D. P. An Equation of State for Associating Fluids. Ind. Eng. Chem. Res. 1996, 35 (11), 4310.

(29) Design Institute for Physical Properties (DIPPR) DIADEM, Information and Data Evaluation Manager. 2016.

(30) Goodman, M. A.; Whittenburg, S. L. Sound Velocity in Simple Carboxylic Acids. J. Chem. Eng. Data 1983, 28 (4), 350.

(31) Dortmund Data Bank www.ddbst.com (accessed Jan 1, 2017).

(32) Bich, E.; Neumann, A.-K.; Vogel, E. Dimerization in Acetic Acid Vapor and Evaluation of poT Measurements with an Equation of State for a Reactive Fluid. Fluid Phase Equilib. 1996, $125(1-2), 67$.

(33) Freeman, J. R.; Wilson, G. M. High-Temperature Vapor-Liquid Equilibrium Measurements on Acetic Acid/Water Mixtures. AIChE Symp. Ser. 1985, 81 (224), 14. 
(34) Liang, X.; Maribo-Mogensen, B.; Thomsen, K.; Yan, W.; Kontogeorgis, G. M. Approach to Improve Speed of Sound Calculation within PC-SAFT Framework. Ind. Eng. Chem. Res. 2012, 51 (45), 14903.

(35) Michelsen, M.; Mollerup, J. Thermodynamic Modelling: Fundamentals and Computational Aspects; Tie-Line Publications, 2007.

(36) Hayden, J. G.; O’Connell, J. P. A Generalized Method for Predicting Second Virial Coefficients. Ind. Eng. Chem. Process Des. Dev. 1975, 14 (3), 209.

(37) Nothnagel, K.-H.; Abrams, D. S.; Prausnitz, J. M. Generalized Correlation for Fugacity Coefficients in Mixtures at Moderate Pressures. Application of Chemical Theory of Vapor Imperfections. Ind. Eng. Chem. Process Des. Dev. 1973, 12 (1), 25.

(38) Prausnitz, J. M.; Lichtenthaler, R. N.; Azevedo, E. G. de. Molecular Thermodynamics of Fluid-Phase Equilibria, 3rd ed.; Prentice Hall PTR, 1999.

(39) Cristancho, D. E.; Acosta-Perez, P. L.; Mantilla, I. D.; Holste, J. C.; Hall, K. R.; IglesiasSilva, G. A. A Method To Determine Virial Coefficients from Experimental ( P, $\rho, T$ ) Measurements. J. Chem. Eng. Data 2015, 60 (12), 3682.

NIST/SEMATECH e-Handbook of Statistical Methods http://www.itl.nist.gov/div898/handbook/ (accessed Jan 1, 2017).

(41) Kennedy, J.; Eberhart, R. Particle Swarm Optimization. In Proceedings of ICNN'95 International Conference on Neural Networks; IEEE, 1995; Vol. 4, pp 1942-1948.

(42) Ferrari, J. C.; Nagatani, G.; Corazza, F. C.; Oliveira, J. V.; Corazza, M. L. Application of Stochastic Algorithms for Parameter Estimation in the Liquid-Liquid Phase Equilibrium Modeling. Fluid Phase Equilib. 2009, 280 (1-2), 110.

(43) Schwaab, M.; Biscaia, Jr., E. C.; Monteiro, J. L.; Pinto, J. C. Nonlinear Parameter Estimation through Particle Swarm Optimization. Chem. Eng. Sci. 2008, 63 (6), 1542.

(44) Shi, Y.; Eberhart, R. A Modified Particle Swarm Optimizer. In 1998 IEEE International Conference on Evolutionary Computation Proceedings. IEEE World Congress on Computational Intelligence (Cat. No.98TH8360); IEEE, 1998; pp 69-73. 
(45) Aparicio-Martínez, S.; Hall, K. R. Phase Equilibria in Water Containing Binary Systems from Molecular Based Equations of State. Fluid Phase Equilib. 2007, 254 (1-2), 112.

(46) Grenner, A.; Schmelzer, J.; von Solms, N.; Kontogeorgis, G. M. Comparison of Two Association Models (Elliott -Suresh - Donohue and Simplified PC-SAFT) for Complex Phase Equilibria of Hydrocarbon - Water and Amine-Containing Mixtures. Ind. Eng. Chem. Res. 2006, 45 (24), 8170.

(47) Kontogeorgis, G. M.; V. Yakoumis, I.; Meijer, H.; Hendriks, E.; Moorwood, T. Multicomponent Phase Equilibrium Calculations for Water-methanol-alkane Mixtures. Fluid Phase Equilib. 1999, 158-160, 201.

(48) Miyamoto, S.; Nakamura, S.; Iwai, Y.; Arai, Y. Measurement of Isothermal Vapor-Liquid Equilibria for Binary and Ternary Systems Containing Monocarboxylic Acid. J. Chem. Eng. Data 2001, 46 (5), 1225.

(49) Rius, A.; Otero, J. L.; Macarron, A. Equilibres Liquide_-vapeur de Mélanges Binaires Donnant Une Réaction Chimique: Systèmes Méthanol—acide Acétique ; Éthanol—acide Acétique; N-Propanol-acide Acétique; N-Butanol-acide Acétique. Chem. Eng. Sci. 1959, $10(1-2), 105$.

(50) Kontogeorgis, G. M. Association Theories for Complex Thermodynamics. Chem. Eng. Res. Des. 2013, 91 (10), 1840.

(51) Tsivintzelis, I.; Kontogeorgis, G. M.; Panayiotou, C. Dimerization of Carboxylic Acids: An Equation of State Approach. J. Phys. Chem. B 2017, 121 (9), 2153.

(52) Sear, R. P.; Jackson, G. Thermodynamic Perturbation Theory for Association into Chains and Rings. Phys. Rev. E 1994, 50 (1), 386.

(53) Avlund, A. S.; Kontogeorgis, G. M.; Chapman, W. G. Intramolecular Association within the SAFT Framework. Mol. Phys. 2011, 109 (December 2013), 1759.

(54) Zhang, M.; Chen, L.; Yang, H.; Ma, J. Theoretical Study of Acetic Acid Association Based on Hydrogen Bonding Mechanism. J. Phys. Chem. A 2017, 121 (23), 4560. 
Table of Contents (TOC) Graphic
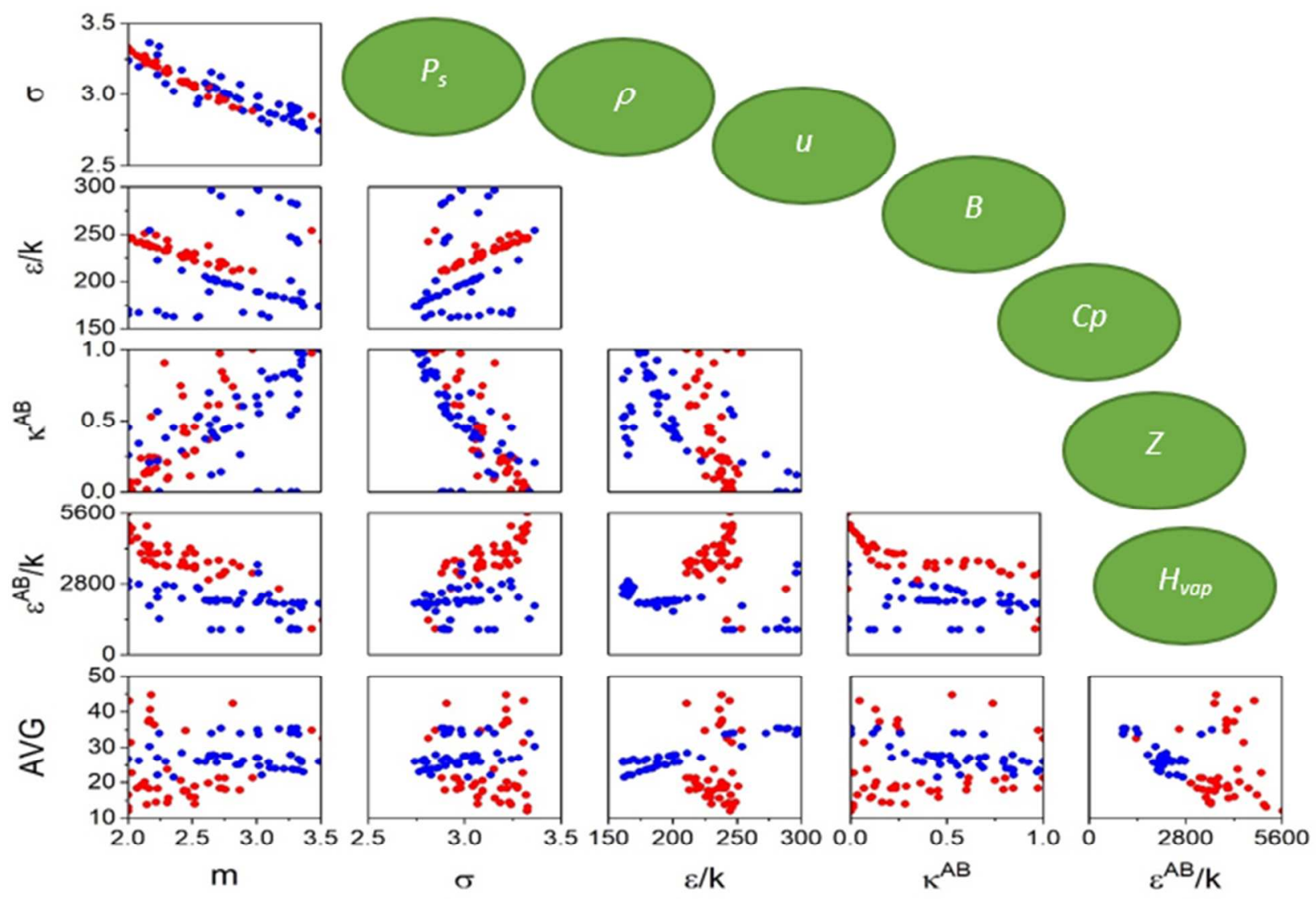